\title{
Radial glia fibers translate Fgf8 morphogenetic signals to generate a thalamic nuclear complex protomap in the mantle layer
}

\author{
Arancha Botella-López ${ }^{1} \cdot$ Raquel Garcia-Lopez $^{2} \cdot$ Ana Pombero $^{2} \cdot$ Salvador Martinez ${ }^{1,3}$
}

Received: 12 December 2017 / Accepted: 9 November 2018 / Published online: 23 November 2018

(c) The Author(s) 2018

\begin{abstract}
Thalamic neurons are distributed between different nuclear groups of the thalamic multinuclear complex; they develop topologically ordered specific projections that convey information on voluntary motor programs and sensory modalities to functional areas in the cerebral cortex. Since thalamic neurons present a homogeneous morphology, their functional specificity is derived from their afferent and efferent connectivity. Adequate development of thalamic afferent and efferent connections depends on guide signals that bind receptors in nuclear neuropils and axonal growth cones, respectively. These are finally regulated by regionalization processes in the thalamic neurons, codifying topological information. In this work, we studied the role of $F g f 8$ morphogenetic signaling in establishing the molecular thalamic protomap, which was revealed by $I g s f 21, P d e 10 a$ and $B t b d 3$ gene expression in the thalamic mantle layer. $F g f 8$ signaling activity was evidenced by pERK expression in radial glia cells and fibers, which may represent a scaffold that translates neuroepithelial positional information to the mantle layer. In this work, we describe the fact that Fgf8-hypomorphic mice did not express pERK in radial glia cells and fibers and presented disorganized thalamic regionalization, increasing neuronal death in the ventro-lateral thalamus and strong disruption of thalamocortical projections. In conclusion, $F g f 8$ encodes the positional information required for thalamic nuclear regionalization and the development of thalamocortical projections.
\end{abstract}

Keywords Fgf8 - Thalamus · Positional information · Diencephalon development · Brain regionalization · Thalamocortical projection

\section{Abbreviations}

\section{AM Anteromedial nucleus}

AV Anteroventral nucleus

BTel Basal telencephalon neuroepithelium

Cx Cortex

DCx Dorsal cortex

Di Diencephalon

DL Dorsolateral nucleus

Garcia-Lopez Raquel and Pombero Ana contributed equally to this work and are listed in alphabetic order.

\section{Electronic supplementary material The online version of this} article (https://doi.org/10.1007/s00429-018-1794-y) contains supplementary material, which is available to authorized users.

\section{Salvador Martinez}

smartinez@umh.es

Instituto de Neurociencias UMH-CSIC, Alicante, Spain

2 IMIB-Arrixaca, ISCIII and University of Murcia, Murcia, Spain

3 CIBER de Salud Mental CIBERSAM ISCIII, Murcia, Spain

$\begin{array}{ll}\text { DPall } & \text { Dorsal pallium } \\ \text { DTel } & \text { Dorsal telencephalon } \\ \text { ETh } & \text { Epithalamus } \\ \text { Hb } & \text { Habenula } \\ \text { Hi } & \text { Hippocampus } \\ \text { Hy } & \text { Hypothalamus } \\ \text { lCx } & \text { Lateral cortex } \\ \text { iml } & \text { Internal medullary lamina } \\ \text { Inh } & \text { FGFR inhibitor } \\ \text { LT } & \text { Lamina terminalis } \\ \text { MCx } & \text { Medial cortex } \\ \text { MPall } & \text { Medial pallium } \\ \text { P1B-P3B } & \text { Basal plates of p1-p3 } \\ \text { pc } & \text { Posterior commissure } \\ \text { PHy } & \text { Peduncular hypothalamus } \\ \text { Pi } & \text { Pineal gland } \\ \text { Po } & \text { Posterior nucleus } \\ \text { PT } & \text { Pretectum } \\ \text { PTh } & \text { Prethalamus } \\ \text { PVP } & \text { Posterior paraventricular nucleus } \\ \text { rf } & \text { Retroflexus fascicle }\end{array}$




$\begin{array}{ll}\text { sm } & \text { Stria medullaris } \\ \text { Se } & \text { Septum } \\ \text { SePall } & \text { Pallial septum } \\ \text { St } & \text { Striatum } \\ \text { TC } & \text { Thalamocortical projection } \\ \text { TCh } & \text { Telencephalic choroidal tissue } \\ \text { TG } & \text { Tectal gray } \\ \text { Th } & \text { Thalamus } \\ \text { TML } & \text { Thalamic mantle layer } \\ \text { VCx } & \text { Ventral cortex } \\ \text { VM } & \text { Ventromedial nucleus } \\ \text { VL } & \text { Ventrolateral nucleus } \\ \text { VPL } & \text { Ventral posterolateral nucleus } \\ \text { VPM } & \text { Ventral posterior medial nucleus } \\ \text { VTel } & \text { Ventral telencephalon } \\ \text { ZLI } & \text { Zona limitans. }\end{array}$

\section{Introduction}

Thalamic projection to specific areas of the cortex $(\mathrm{Cx})$ is fundamental in the development of conscious sensory and motor functions, and thalamic neurons projecting to the $\mathrm{Cx}$ present homogeneous morphology (Jones 2007; Clascá et al. 2012). Nevertheless, target specificity in the thalamocortical projection (TC) constitutes one of the most prominent high-level processes in the developing mammalian brain (Jones 2001; Clascá et al. 2009; Sherman and Guillery 2011). The organized pattern of TC is a consequence of elaborate mechanisms of positional information in thalamic neurons and axonal navigation (Garel and López-Bendito 2014). The functional complexity of this system requires positional information, which is represented in the germinative epithelium of the diencephalon (Di) and Cx as molecular maps specifying neural identities (Rakic 1988; O’Leary et al. 2007; Nakagawa and Shimogori 2012; Martinez-Ferre and Martinez 2012; Elsen et al. 2013).

The expressions of Netrin1 (Ntn1), Slit 1, Robo, Sema3A and EphrinA5 in the ventral telencephalon (VTel) act as molecular signals for thalamic axon navigation, to innervate the Cx (Andrews 2006; Bagri et al. 2002; Bielle et al. 2011; Bonnin et al. 2007; Braisted et al. 2000; López-Bendito et al. 2006; Serafini et al. 1996). Axons grow from the thalamus (Th) to prethalamus (PTh), entering the internal capsule between embryonic days 12-15 (E12 to E15), reaching the cortical subplate (SP) at E14-16, and invading Cx by E18 (Ghosh et al. 1990; Squarzoni 2015).

During early embryogenesis (E9-E11), diencephalic neuroepithelial regions are specified by the expression of genes coding for morphogenetic signals and molecular regulators of cellular identities (Puelles et al. 1987; Puelles and Rubenstein 1993; Stoykova and Gruss 1994; Redies 1995; Redies et al. 2000; Kataoka and Shimogori 2008; Suzuki-Hirano et al. 2010; Nakagawa and Shimogori 2012; Navarro-Garberi et al. 2016). Therefore, neuroepithelial regionalization consists in a primordial bidimensional (2D) molecular map that defines antero-posterior (AP) and ventro-dorsal (VD) positional information. Subsequently, postmitotic neurons migrate into the thalamic mantle layer (TML) to either become grouped into compact masses (thalamic nuclei) or remain disaggregated inside crossing axonal tracts (reticular thalamic areas). According to their position in the TML, these neurons will express specific genetic patterns and follow different programs of structural and functional maturation. However, little is known about how regional neuroepithelial information is translated into the TML. To unravel the process of TML regionalization; that is, how the neuroepithelial map is translated to the TML and its role in the final neuronal fate, we analyzed the expression of three genes: Mus musculus immunoglobulin superfamily, member 21 (Igsf21); Phosphodiesterase 10A (Pde10a) and BTB (POZ) domain containing 3 (Btbd3). These genes exhibit a complementary expression pattern in the TML at E13.5 and E14.5, when the TML is still a structurally homogeneous mass of neurons, and TC pioneer axons are reaching the Cx. Next, we explored whether TML regionalization is regulated by signals that specify the neuroepithelial map. To this end, since the Fibroblast growth factor 8 ( Fgf8) gene is expressed in the dorsal diencephalon (Supplementary Fig. $\mathrm{S} 1$ ) and the $F g f 8$ signal is involved in specifying thalamic progenitors (Kataoka and Shimogori 2008; Martinez-Ferre and Martinez 2009), the thalamic regionalization and TC projection were studied in $F g f 8$ hypomorphic mice (Fgf $8^{\text {null/ }}$ ${ }^{n e o}$ ), which express very low levels of $F g f 8$ in the Di (Meyers et al. 1998; Martinez-Ferre and Martinez 2009). Previously, we studied the role of $F g f 8$ in early diencephalic development, also using $F g f 8$ hypomorphic mice, showing that the progressive reduction of $F g f 8$ expression in the dorsal diencephalon results in increasing alterations of cellular proliferation and neuronal migration. Although $F g f 8$ was involved in specifying epithalamic and thalamic growth, no effect was observed on the formation of the zona limitans and early diencephalic regionalization (Martinez-Ferre and Martinez 2009). Therefore, we decided to analyze the potential role of $F g f 8$ in later-stage TML regionalization.

Moreover, although previous studies have related $F g f 8$ to axonal guidance (Garel et al. 2003; Yamauchi et al. 2009; Atkinson-Leadbeater et al. 2010), we also wanted to study the role of this morphogen in TC development.

Fgf8 signaling activity in TML cells was studied through the activation of $p E R K$ expression (Echevarria et al. 2005), which was detected in diencephalic radial glia cells and fibers. We showed that $p E R K$ expression in the radial glia controls the proliferation of thalamic progenitors, as well as the survival and regionalization of neurons in the TML. We also evidenced a prominent role of the $F g f 8$ signal in thalamic 
axon navigation to the $\mathrm{Cx}$. These findings demonstrate that radial glia are a fundamental scaffold for translating $2 \mathrm{D}$ maps of ventricular diencephalic specification to the mantle layer, where a 3D thalamic protomap is established, regulating neuronal survival and thalamic nuclear specialization.

\section{Materials and methods}

\section{Mouse lines and genotyping}

All animal experiments were performed in compliance with Spanish (RD 223/1998) and European Union laws on the protection of animals used in experimentation (Council Directive 86/609/EEC) and approved by the UMH-CEIE committee.

Fgf $8^{\text {neo/+ }}$ and $\mathrm{Fgf}^{\text {null/++ }}$ mice were bred to produce Fgf8 ${ }^{\text {null/neo }}$ mutants (C57BL/6 genetic background). PCR genotyping was performed as described by (Chi et al. 2003). The morning the vaginal plug was detected was considered embryonic day 0.5 (E0.5). Heterozygous $\mathrm{Fgf}^{\mathrm{neo} /+}, \mathrm{Fgf}^{\text {null//+ }}$ embryos did not present any different structural phenotype and were used together with $\mathrm{Fgf}^{+/+}$embryos as controls.

The mouse embryos were fixed overnight by immersion in $4 \%$ paraformaldehyde in phosphate-buffered saline solution (PBS; 0.1M, pH 7.4) at $4{ }^{\circ} \mathrm{C}$.

\section{In situ hybridization}

The mouse brains were paraffin embedded (Gemcut, Spiele no. 24364-1) and sectioned in $7 \mu \mathrm{m}$-thick sagittal and transverse sections. The sections were washed with phosphatebuffered saline (PBS; pH 7.4, 1X)-0.1\% Tween-20 (Sigma Aldrich, Steinhem, Germany) and incubated in hybridization solution: deionized formamide 50\%, standard SALT buffer $1 \mathrm{X}$ pH 7.5, Dextran sulfate 10X (Sigma-Aldrich), Denhart 1X (Sigma-Aldrich), yeast tRNA $2 \mathrm{mg} / \mathrm{ml}$ (Sigma-Aldrich) and water free of RNAase and DNAase (Sigma-Aldrich), for $1 \mathrm{~h}$ at $67{ }^{\circ} \mathrm{C}$. Thereafter, the sections were hybridized overnight at $67{ }^{\circ} \mathrm{C}$ in hybridization solution containing $4 \mu \mathrm{l} / \mathrm{ml}$ riboprobe. Next, they were incubated overnight at $4{ }^{\circ} \mathrm{C}$ with alkaline phosphatase-coupled anti-digoxigenin antiserum (1:3500; Roche Diagnostics, Mannheim, Germany); followed by NBT/BCIP (nitroblue tetrazolium/5bromo-4-chloro-3-indolyl phosphate) solution as a chromogenic substrate to obtain blue labelling (Boehringer, Mannheim, Germany). The sections were dehydrated and covered with Eukitt ${ }^{\circledR}$. All images were taken using a Leica stereoscope (Leica MZ16FA) and digital cameras (Leica DC500, DC250). The contrast and brightness of the photomicrographs were adjusted in Adobe PhotoShop, Macintosh or PC version, CS3 (Adobe Systems, San Jose, CA). Digoxigenin-11-UTP labelled RNA probes were prepared from full-length cDNA clones provided by Source BioScience imaGenes: Igsf21 (NM_198610.2) 32-1990 pb, Pde10a (NM_011866.2) 402-3324 pb; Btbd3 (NM_145534.2) 30-2439 pb. The Ntn1 probe was provided by O. Reiner, and Slit1 and Slit2 probes by O. Marín.

\section{Immunohistochemistry}

Paraffin sections were treated with $0.3 \%$ hydrogen peroxide in PBS $+0.3 \%$ Triton (PBT) for 15 min to inactivate endogenous peroxidase activity, blocked in PBT and 3\% BSA and incubated with anti-DCC antibody (1:100; SantaCruz \#sc-6535). Then they were incubated with secondary biotinylated antiserum for $2 \mathrm{~h}$ at room temperature (RT; Vector, Burlingame, CA, USA), washed with PBT and incubated in avidin-biotin complex (ABC kit; Vector; $0.003 \%$ dilution) for $1 \mathrm{~h}$ at RT. The immunolabeling was revealed by $0.05 \%$ diaminobenzidine (DAB; Vector Laboratories SK-4100) in $0.05 \mathrm{M}$ Tris buffer ( $\mathrm{pH} 7.6$ ), containing $0.03 \% \mathrm{H}_{2} \mathrm{O}_{2}$. For anti-dpERK immunohistochemistry (Rabbit anti-dpERK, 1:250; Cell Signaling Technology \#9101), the brains were embedded in $4 \%$ agarose in PBS, and $70 \mu \mathrm{m}$ sections were cut in coronal planes using a Leica vibratome (VT1000S). For these sections, the immunolabelling was revealed with $0.05 \% \mathrm{DAB}, 0.025 \%$ ammonium nickel sulfate hexahydrate and $0.03 \% \mathrm{H}_{2} \mathrm{O}_{2}$ in PBS.

Fluorescent immunohistochemistry: paraffin sections were incubated overnight with rabbit anti-phospho histone 3 (1:500; Upstate \#06-570), rabbit anti-Caspase 3 (1:250; Cell Signaling \#9661-s), rabbit anti-dpERK ( 1 :250; Cell Signaling Technology \#9101) and mouse anti-GFAP (1:1000; Millipore \#MAB360). After this, sections were incubated with anti-rabbit Alexa Fluor 488 (Molecular Probes \#21206) and anti-mouse biotinylated antibody (1:200; Vector \#BA-9200), followed by Cy3-streptavidin (1:500; Amersham PA\#43001) and then counterstained with DAPI (4', 6-Diamidino-2-Phenylindole, dihydrochloride; Sigma) a fluorescent nuclear dye, diluted in PBS at $0.001 \%$ and incubated for $10 \mathrm{~min}$ at RT.

\section{Cell proliferation and apoptosis analysis}

In order to assess possible alterations in proliferation or cell death in $\mathrm{Fgfr}^{\text {null/neo }}$ mutants paraffin sections were immunostained with anti-phospho histone 3 and anti-Caspase 3, as described above. Then, the number of positive cells for the corresponding antibody was quantified by counting positive cells per unit area (mitotic index). This unit area was a box of $10500 \mu \mathrm{m}^{2}$ placed on the neuroepithelium from the epithalamus to the thalamus, following a previously described protocol (Martinez-Ferre and Martinez 2009). Three consecutive sections were counted per animal and three animals were used for each stage and genotype. 

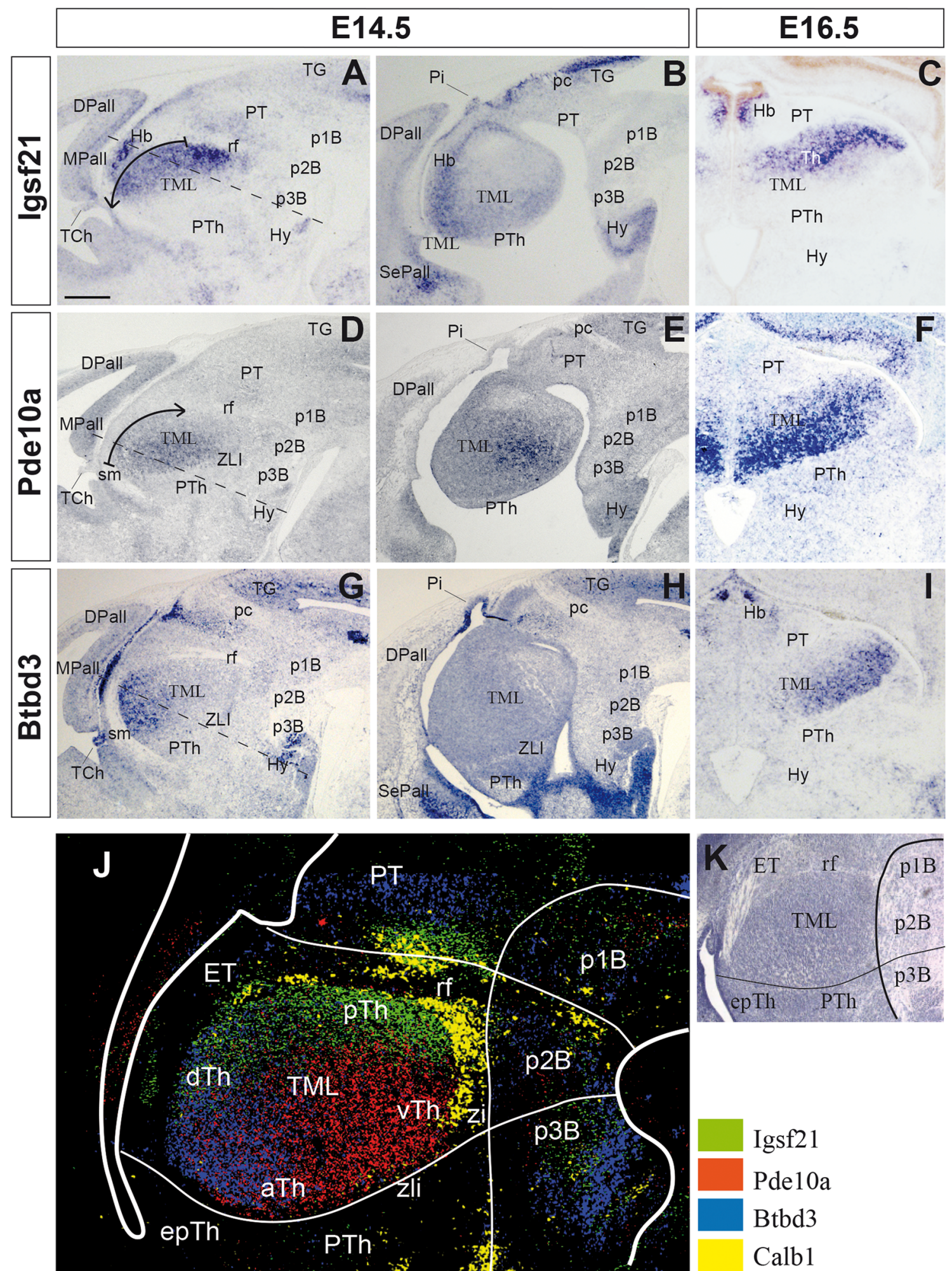

\section{Organotypic cultures}

E13.5 organotypic cultures of embryonic mouse brains (Echevarría et al. 2001): the neural tube, like an "open book", was transferred to sterile Petri dishes and placed on floating polycarbonate membrane $8 \mu \mathrm{m}$ pore size filters (Nunc) with $10 \%$ fetal bovine serum in DMEM culture medium (Gibco-Life Technologies). Glutamax ( $2 \mathrm{mM}$; Gibco-Life Technologies) and Penicillin-Streptomycin (100U/ ml-100 $\mu \mathrm{g} / \mathrm{ml}$; Gibco-Life Technologies) were added 
4Fig. 1 Igsf21, Pde10a and Btbd3 expression in the developing thalamus of a mouse. Igsf21, Pde10a and Btbd3 expression in E14.5 and E16.5 embryos, sagittal (lateral to medial, $\mathbf{a}, \mathbf{b} ; \mathbf{d}, \mathbf{e}$; g, h) and transversal (c, f, i) sections. a-c Thalamic Igsf 21 expression is detected as a posteriorly to anteriorly decreasing gradient (arrow; a). d-f $P d e 10 a$ is mainly detected in the anterior Th, with a rostro-caudal decreasing gradient (arrow; d). $\mathbf{g}-\mathbf{i}$ Btbd3 is expressed in the most dorsal region, showing a dorso-ventral gradient. $\mathbf{j}$ Complementary expression of these genes in the thalamic mantle layer, shown in a composite picture using equivalent sagittal section planes aligned by overlapping three stable anatomical references (rf, mamillary bodies, ETh-telencephalic flexure). Color-coded overlays represent different gene expression patterns (see insert). k Nissl's staining of E14.5 Th, showing the homogeneous distribution of neurons in the mantle layer. Dashed lines in $\mathbf{a}, \mathbf{d}$ and $\mathbf{g}$ correspond to the plane of the transversal sections (c, f, i). Scale bar $200 \mu \mathrm{m}$

to the culture medium. The organotypic cultures were incubated for $1 \mathrm{~h}$ in a sterile incubator $\left(37^{\circ} \mathrm{C}, 5 \% \mathrm{CO}_{2}\right)$, after which the medium was changed to Neurobasal/B-27 (Gibco BRL, Life Technologies Inc, Gaithersburg, MD).

Beads were implanted in the dorsal Di at E13.5 as described previously (Echevarría et al. 2001; MartinezFerre and Martinez 2009). Affi-Gel Blue Gel beads (Bio$\mathrm{Rad})$ were rinsed in PBS and then soaked overnight at $4{ }^{\circ} \mathrm{C}$ in a solution of $25 \mu \mathrm{g} / \mathrm{ml}$ Dkk-1 protein in PBS/0.1\% BSA (Sigma), or with the FGF8 inhibitor SU5402 $40 \mu \mathrm{M}$ (Calbiochem, La Jolla, CA, USA) in dimethyl sulfoxide (DMSO; Sigma), respectively. The beads were then rinsed several times in $1 \mathrm{mg} / \mathrm{ml}$ BSA solution or DMSO and implanted into the explants. For the control experiments, beads were soaked in PBS $/ 0.1 \%$ BSA in the same manner. The embryos were fixed in $4 \%$ PFA at $4{ }^{\circ} \mathrm{C}$, overnight, 2 days after implantation.

In some cases, the organotypic cultures were paraffin embedded, cut and processed immunohistochemically using Rabbit anti-Caspase-3 (1:250; Cell Signaling Technology \#9661).

\section{Axonal Tracing}

For axonal tracing, small DiI crystals (1,1'-dioctadecyl 3,3,3',3'-tetramethylindocarbocyanine perchlorate; Molecular Probes) were inserted into the Th of hemi-dissected brains. These embryonic brains or cultured slices were incubated for 7 days, or 2 days, respectively, in $4 \%$ PFA at $37^{\circ} \mathrm{C}$. The brains were cut using a Leica vibratome (VT1000S) into $80-100 \mu \mathrm{m}$ sections and counterstained with DAPI.

\section{Results}

\section{Disorganization of thalamic regionalization in Fgf8 ${ }^{\text {null/neo }}$ hypomorphic mice}

At E13.5-14.5, the TML seems to be a structurally homogeneous mass of neurons (Nakagawa and O'Leary 2003) (Fig. 1; Fig. S2). To explore whether TML is already molecularly patterned at these stages, transcription databases were assessed to identify genes with heterogeneous expression in the TML (http://www.eurexpress.org and http://www.brain-map.org). As a result, 90 genes were identified with expression in the TML at E13.514.5, but only 12 genes showed clear regional expression: BC055811, BC062109, Btbd3, EG628779, Elmo1, Igsf2, Pde10a, Rapgef3, Slc6a7, Slitrk6, Srgap2 and Trim9. From these, we selected three showing clear heterogeneous complementary expression in the TML: Igsf21, $P d e 10 a$ and Btbd3 (Figs. 1, 2). Thus, their expression pattern was studied in the TML from E14.5 to E17.5. First, a decreasing caudal-to-rostral gradient of Igsf 21 expression was observed at E14.5 (Fig. 1a, b). Conversely, Pde10a transcripts showed a decreasing rostral-to-caudal gradient (Fig. 1d, e), whereas Btbd3 displayed a decreasing dorsalto-ventral gradient in the TML (Fig. 1g, h). Second, at E16.5, Igsf 21 expression was detected in the caudal and dorsal Th (Fig. 1c). Pde10a-expressing cells were mainly mapped in the anterior and ventral TML, with stronger medial than lateral expression (Fig. 1f), while Btbd3 was restricted to the most ventrolateral region (Fig. 1i). Finally, at E17.5, when nuclear segregation was clear in the TML, Igsf 21 was expressed in the posterior and dorsal thalamic nuclei (Fig. 2a-c), whereas Pde10a showed decreasing medial-to-lateral expression in the ventral thalamic nuclei (Fig. 2d-f). Furthermore, a Btbd3 signal (Fig. 2g-i) was detected in the anterior nucleus (Fig. 2g), showing a decreasing lateral-to-medial gradient in the ventrolateral nuclei (VL; Fig. 2g, i). The complementarity between these expressions in the TML was clear when adjacent sections were combined, matching at least three stable anatomical references to superpose three consecutive sections, both in sagittal and transverse sections (Figs. 1j, $2 \mathrm{j}, 1)$. These compositions were generated by combining images from consecutive series from the same animal to establish accurate overlapping. Dorsal and posterior nuclei expressed Igsf21, ventromedial nuclei expressed Pde10a, and VL expressed Btbd3. A sharp molecular boundary was detected along the radial extension of the TML, separating the dorsal and ventral nuclei, where the thalamic internal medullary lamina (iml) would develop (Fig. 21).

To determine the role of $F g f 8$ in TML regionalization, we studied the expression patterns of Igsf21, Pde10a and 


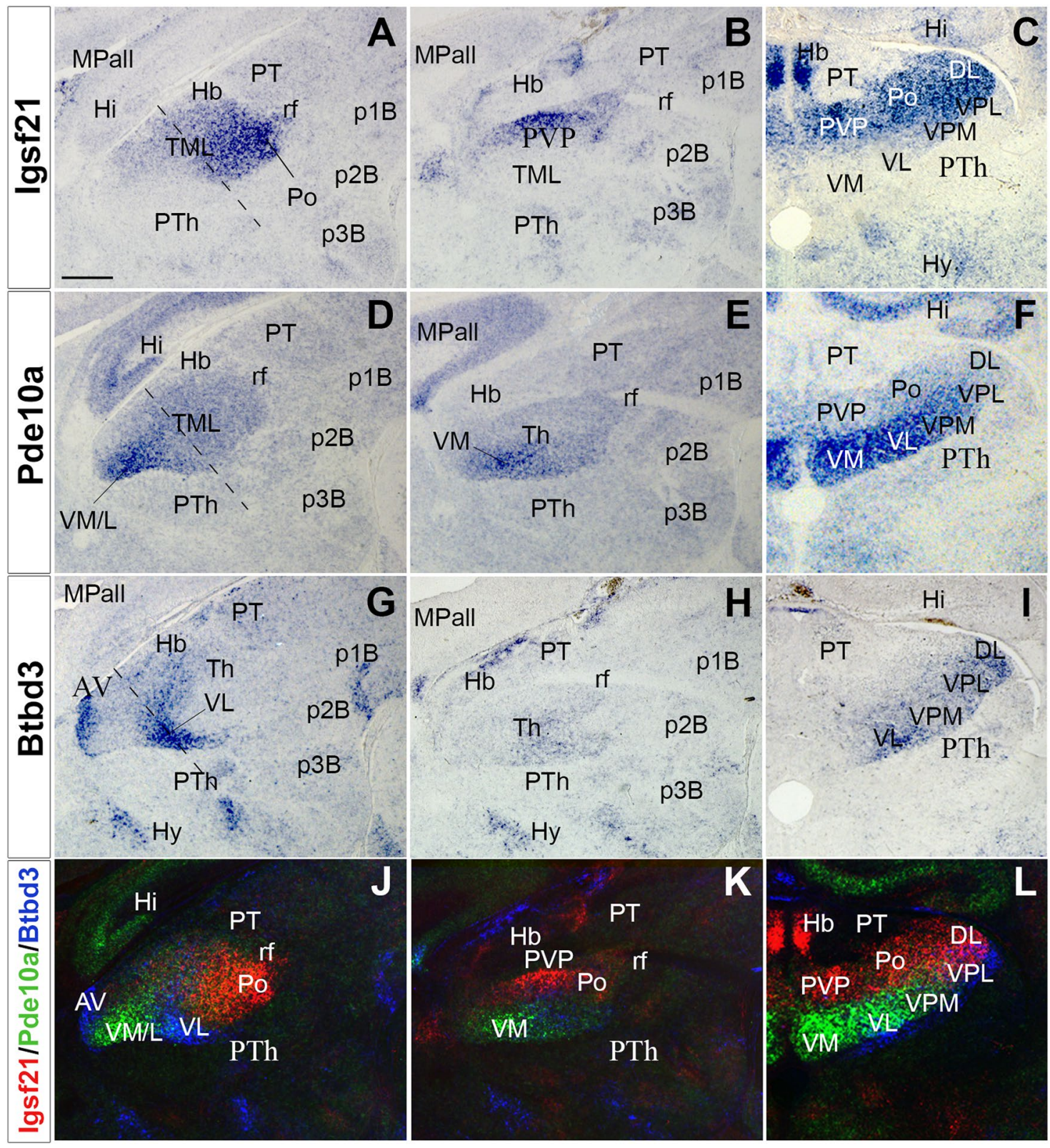

Fig. 2 Igsf21, Pde10a and Btbd3 expression in perinatal stages. Igsf21, Pde10a and Btbd3 expression in E17.5 embryos, sagittal (lateral to medial, $\mathbf{a}, \mathbf{b} ; \mathbf{d}, \mathbf{e} ; \mathbf{g}, \mathbf{h})$ and transversal $(\mathbf{c}, \mathbf{f}, \mathbf{i})$ sections. Colorcoded overlays of hybridizations for Igsf21 (red), Pde10a (green) and $B t b d 3$ (blue) genes $(\mathbf{j}-\mathbf{l})$. a-c Igsf21 is strongly expressed in Po and DL nuclei. d-f $P d e 10 a$ is strongly labelled in the VM, VL and VPM. $\mathbf{g}-\mathbf{i} B t b d 3$ displays a weak signal in VL, VPM, VPL and DL nuclei. $\mathbf{j}-\mathbf{l}$ pseudo-colored superposition of adjacent sections depicting the complementary expression of the three genes. The molecular boundary between dorsal and ventral nuclei is clearly detectable, mainly between Igsf 21 and Pde10a expression domains. Dashed lines in a, $\mathbf{d}$ and $\mathbf{g}$ correspond to the plane of the transversal sections $(\mathbf{c}, \mathbf{f}, \mathbf{i})$. Scale bar: $200 \mu \mathrm{m}$

were reduced in Po and DL nuclei (Fig. 3a-d) compared to controls $(n=4)$. Moreover, upregulation of this gene was detected in scattered cells of the lateral ventral nuclei, VPM/L (Fig. 3c, d). The Pde10a gene was upregulated in medio-ventral nuclei, which extended dorsally in $\mathrm{Fgf}^{\text {null/neo }}$ mice $(n=4)$ and downregulated in the VPM/L ( $n=4$; Fig. $3 \mathrm{e}-\mathrm{h})$. The expression of $B t b d 3$ was 


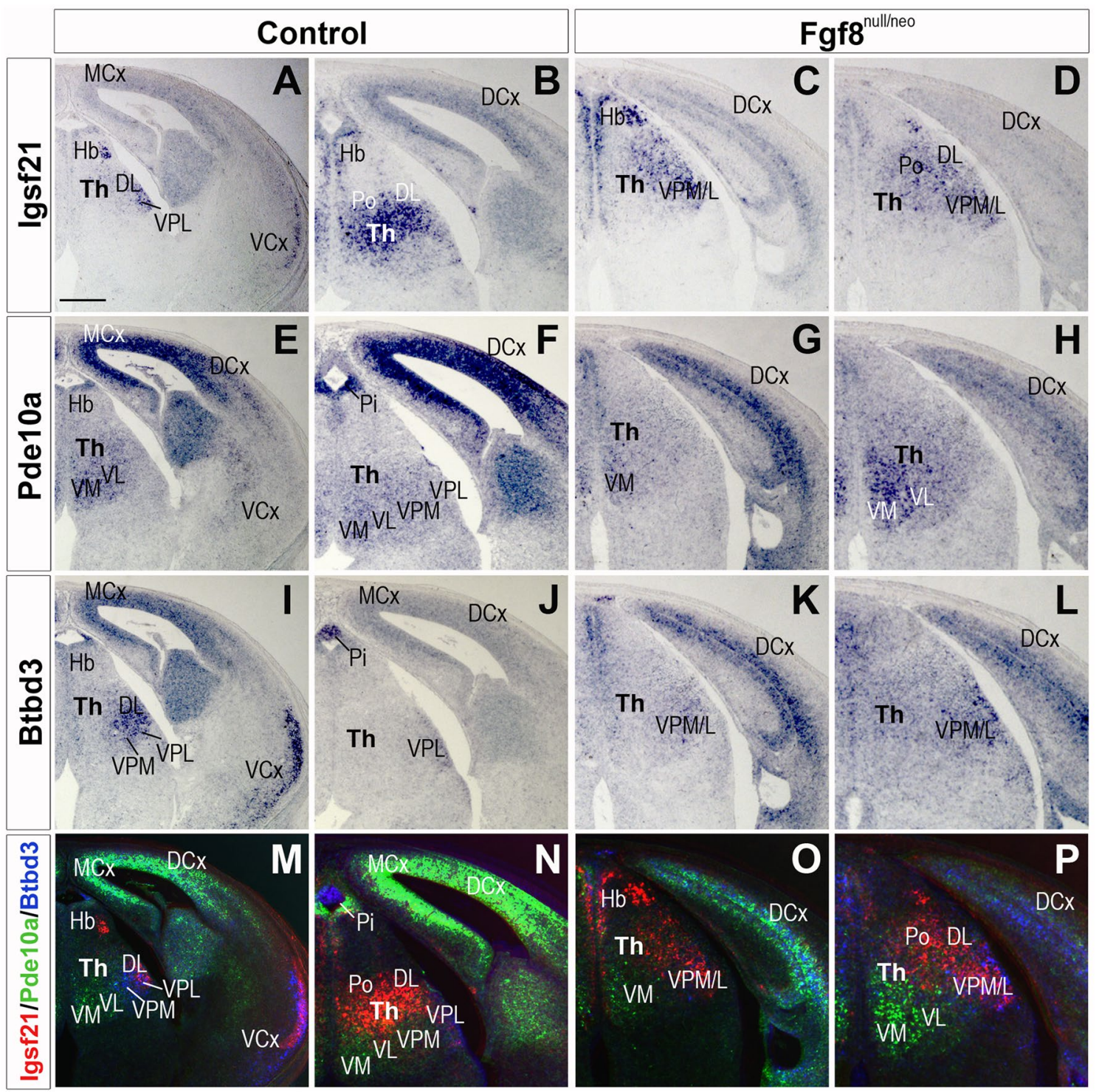

Fig. 3 Igsf21, Pde10a and Btbd3 expression in control and Fgf8 ${ }^{\text {null/neo }}$ mice at E15.5. a-d Igsf21 expression, e-h Pde10a expression, $\mathbf{i}, \mathbf{l}$ Btbd 3 expression and $\mathbf{m}-\mathbf{p}$ overlay of the three gene expressions in control and Fgf $8^{\text {null/neo }}$ embryos, transverse sections. Igsf 21 is detected mainly in the thalamic DL and Po nuclei in the control mice $(\mathbf{a}, \mathbf{b})$. In Fgf $8^{\text {null/neo }}$ mice, Igsf 21 is downregulated in DL/Po and ectopically detected in abundant cells of VPM and VPL nuclei (c, d). Pde10a is expressed in the ventral nuclei, VM, VL, VPM and
VPL, in controls (e, f) while it is upregulated and in the mutant VM nucleus, which appears extended dorsally $(\mathbf{g}, \mathbf{h}) . B t b d 3$ is weakly detected in VPM and VPL nuclei in Fgf $8^{\text {null/neo }}(\mathbf{k}, \mathbf{l})$ compared to controls $(\mathbf{i}, \mathbf{j})$. Color-coded overlays depict the complementary expression gradient of the three genes in the control $(\mathbf{m}, \mathbf{n})$, and diffuse labelling in the mutant mouse $(\mathbf{o}, \mathbf{p})$. The molecular boundary between dorsal and ventral nuclei appears disrupted by intermingled cell expression of dorsal and ventral markers. Scale bar $200 \mu \mathrm{m}$ predominantly observed in the VPM/L and DL nuclei in control mice (Fig. 3i, j), being expressed more weakly in the mutant Th (Fig. 3k, 1). At E17.5, the TML of hypomorphic mice $(n=4)$ was clearly smaller, there was no Igsf 21 expression in the anterior thalamic pole (AM; Fig. 4a, a', $\left.\mathrm{j}, \mathrm{j}^{\prime}\right)$ and a reduced cell expression density in dorsal, lateral and posterior thalamic nuclei. Scattered $I g s f 21+$ cells extended ventrally into the dorsal nuclei domain and intermixed with some remaining $B t b d 3$-expressing cells
(Fig. 4b, c, b', c', k, 1, k', 1'). Pde10a gene expression was still upregulated in the VM and extended dorsally in Fgf $8^{\text {null/neo }}$ mice, and decreased expression was observed in the VPM/L $\left(n=4\right.$; Fig. $\left.4 \mathrm{~d}-\mathrm{f}^{\prime}, \mathrm{k}, 1, \mathrm{k}^{\prime}, \mathrm{l}^{\prime}\right)$, whereas $B t b d 3$ was downregulated in the VPM/L and DL in the mutant mouse compared to the control $\left(n=4\right.$; Fig. $4 \mathrm{~g}-\mathrm{i}^{\prime}$, $\left.\mathrm{k}-1, \mathrm{k}^{\prime}-\mathrm{l}^{\prime}\right)$. Overlay compositions of Igsf 21, Pde10a and Btbd 3 expressions, generated using consecutive sections of different gene series from the same animal, to preserve 


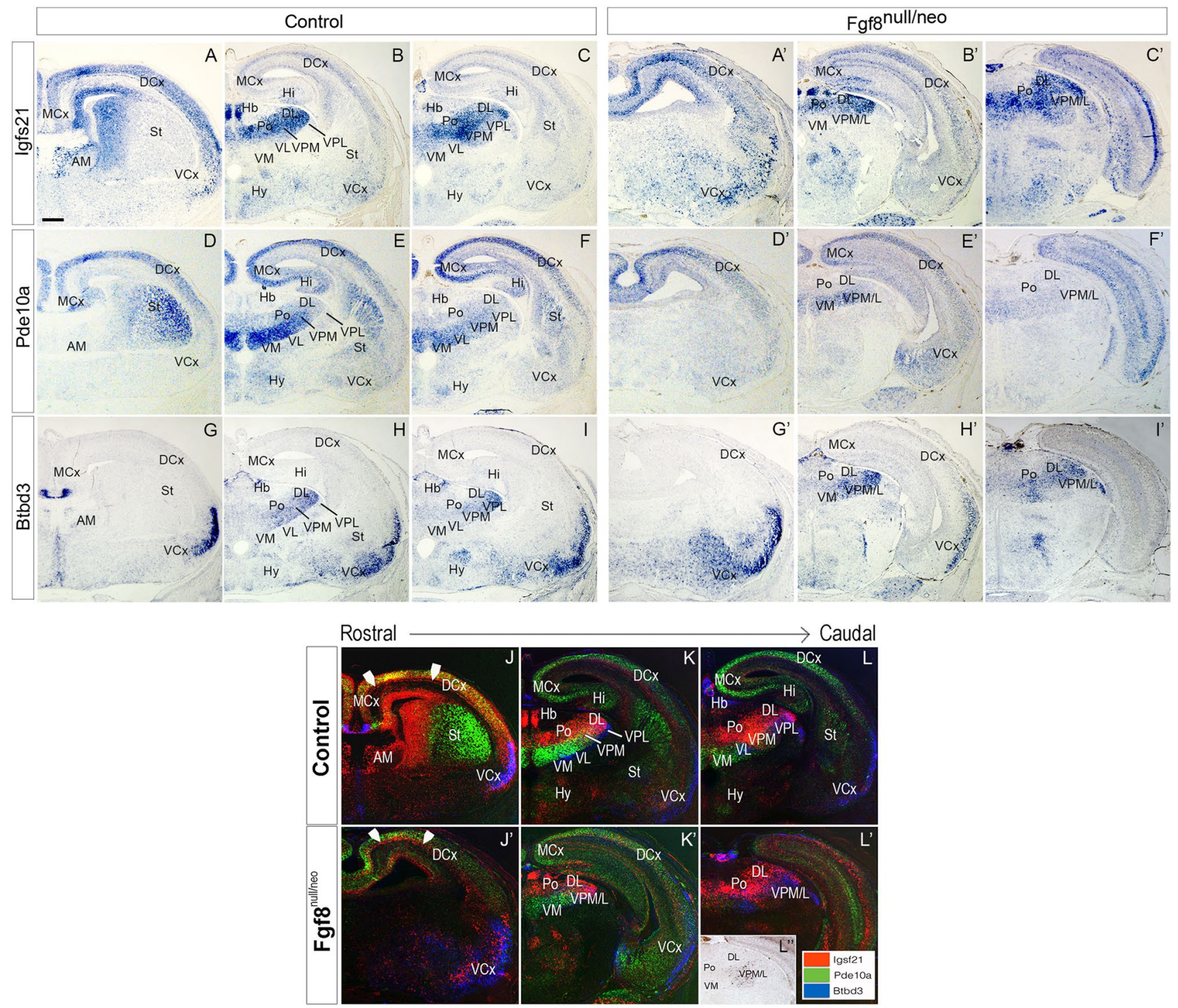

Fig. 4 Igsf21, Pde10a and Btbd3 expression in the Cx of a Fgf8 $8^{\text {null/neo }}$ mouse in perinatal stages (E17.5). In situ mRNA hybridization in transversal brain sections of Igsf21, Pde10a and Btbd3 genes in control $(\mathbf{a}-\mathbf{i})$ and in Fgf8 ${ }^{\text {null/neo }}\left(\mathbf{a}^{\prime}-\mathbf{i}^{\prime}\right)$ mice. Images are adjacent sections, ordered from rostral to caudal, obtained from the same animal to match the different areas accurately $\left(\mathbf{j}-\mathbf{I}^{\prime}\right)$. Color-coded overlays of hybridizations for Igsf21 (red), Pde10a (green) and Btbd3 (blue) genes in E17.5 transversal sections of control $(\mathbf{j}-\mathbf{l})$ and Fgf $8^{\text {null/neo }}$ $\left(\mathbf{j}^{\prime}-\mathbf{l}^{\prime}\right)$ embryos, from rostral to caudal ( $\mathbf{j}$ to $\mathbf{l}$ and $\mathbf{j}^{\prime}$ to $\mathbf{l}^{\prime}$, respectively). Arrowheads indicate the clear subplate cell layer (SP) in the wild type

the highest possible accuracy, showed that the molecular boundary between the dorsal and ventral thalamic nuclei was still detectable in mutant brains in the ventro-medial region, but was completely disrupted in the lateral regions, both at E15.5 and E17.5 (Fig. 3o, p and Fig. 4k', $1^{\prime}$ ). (a) that appears disorganized in the Fgf $8^{\text {null/neo }}$ mouse. The overlap of the three genes confirms the complementary expression pattern in this region in the control, but not Fgf ${ }^{\text {null/neo }}$ mice, where the anterior nuclear complex is not apparent and there is a reduction of ventrallateral nuclei, which are invaded by the dorso-lin ateral marker gene. The boundary between dorsal and ventral nuclei is disrupted by bidirectional cellular dispersion across its domain. $\mathbf{l}^{\prime \prime}$ is a caudal transversal section from an Fgf8 ${ }^{\text {null/neo }}$ mutant mouse, immunostained against caspase 3, where VPM/L is clearly affected. Scale bar: $200 \mu \mathrm{m}$

These results indicate that $\mathrm{Fgfr}^{\text {null/neo }}$ embryos present strong alterations in TML regionalization, showing a distorted expression pattern for the Igsf 21, Pde $10 a$ and Btbd3 genes in the TML, revealing the absence of ventral and dorsal nuclear specification and the formation of the internal medullary lamina between these when $F g f 8$ expression is reduced (Figs. 3, 4). 


\section{Altered telencephalic expression of Igsf 21 and Pde 10a in Fgf8 ${ }^{\text {null/neo }}$ mice}

The expression of Igsf21, Pde10a and Btbd3 in control $(n=4)$ and mutant $(n=4)$ embryos at E17.5 was analyzed in transversal sections of the anterior telencephalon (Fig. 4). In control embryos, Igsf 21 was strongly expressed in the subplate (SP; arrowhead Fig. $\left.4 \mathrm{j}, \mathrm{j}^{\prime \prime}\right)$ and coexpressed with Pde10a in the cortical plate, while in the mutant embryos, Igsf 21 expression presented as a thick layer of neurons below and segregated from the cortical plate, labelled by Pde10a expression (Fig. 4a, a', d, d' and arrowhead in j, j'). No significant differences were observed in the expression pattern of $B t b d 3$ in the Cx (Fig. 4g-i'). Nevertheless, in mutant mice, the expression of PdelOa was strongly reduced in the dorsal layers of the medial Cx (Fig. 4d-f'). In addition, in the basal ganglia, while Pde10a was strongly expressed in the embryonic striatum of controls (St; Fig. 4d, j), in Fgf8 ${ }^{\text {null/neo }}$ mice this expression was not detected (Fig. $4 d^{\prime}, j^{\prime}$ ).

\section{Reduced cell proliferation and increased cell death in the Fgf8 ${ }^{\text {null/neo }}$ mouse thalamus}

Previous studies have shown that $F g f 8$ works as a cell proliferation signal (Lee et al. 1997; Xu et al. 2000; Sun et al. 2002; Martinez-Ferre and Martinez 2009) and as a cell survival factor (Sun et al. 2002; Storm et al. 2003; Chi et al. 2003). To explore cell proliferation in TLM, Fgf8 mutants were analyzed at E12.5 and E14.5 by detecting the expression of the M-phase cell cycle marker, PH3. In control embryos, the rate of cell proliferation in the Di was higher at E12.5 $(93 \pm 7)$ than in later developmental stages (E14.5, $44 \pm 2$; Fig. 5a, b, g). Moreover, at both E12.5 and E14.5, control embryos ( $n=3$ for each stage) showed a significantly higher mitotic index (number of positive cells per unit area) in Th and Eth than mutants ( $n=3$ for each stage; $p=0.021$ and $p<0.05$ ), respectively (Fig. 5a, b, d, e, g); but no differences in mitotic distribution were observed.

To explore if cell death could explain regional alteration in $F g f 8$ hypomorphic mice, we analyzed the expression of caspase-3, which was not detected in the control TML (Fig. 5c). We observed dying cells in the $F g f 8$ mutant embryos in the VPM/L of the TML at E15.5 (Fig. 5f) and E17.5 (Fig. 41").

These results indicate that both proliferation and cell death in the Th are affected by the decreased expression of Fgf8. Interestingly, cell death appeared selective in the ventrolateral TML, the most distant region from the ventricular source of $F g f 8$ signal.

To evidence a reduction in the $F g f 8$ signal in the TML, we used immunohistochemistry to study the expression of pERK, which is induced when the Fgf signal binds tyrosine kinase Fgf receptors (Echevarria et al. 2005). At E14.5, the dorsal Th ventricular epithelium was strongly positive for pERK in WT mice $(n=4$; Fig. $5 \mathrm{~h}, \mathrm{i})$. This expression was also observed with a fibrillar pattern in the neuroepithelium crossing the TML, towards the pial surface (Fig. $5 \mathrm{j}$ ). That expression seemed to overlap with radial glia fibers and appeared more strongly stained at the level of the thalamic VPL/M and ZLI regions (Fig. 5h-j). The expression of pERK was completely absent in the Fgf ${ }^{\text {null/neo }}$ mice dorsal Th $(n=4)$, both in the ventricular epithelium and TML fibers (Fig. 5k, 1). To test whether radial glia fibers were expressing pERK, we performed double immunohistochemistry against pERK and GFAP, and observed that, as expected, there was co-expression of these antibodies (Fig. 5m-r). Moreover, since the expression of pERK in blood vessels has recently been reported by our group (Pombero et al. 2018), we decided to explore this in the thalamus, as a control for pERK expression in mutants. The vascular pERK expression was similar in WT and Fgf8 ${ }^{\text {null/neo }}$ TML (Fig. 5h-1). The presence of normal radial glia cells and fibers in Fgf ${ }^{\text {null/ }}$ ${ }^{\text {neo }}$ mice at these stages were detected through anti-GFAP and vimentin immunohistochemistry (data not shown). These results suggest that $F g f 8$ morphogenetic activity in the ventricular epithelium is translated to the TML by the expression of pERK in radial glia fibers, which seems to be required for cell survival and appropriate nuclear patterning.

To demonstrate that the $F g f 8$ signal regulates pERK expression in the thalamic radial glia, we performed "open book" E14.5 neuroepithelial explants of the WT (Fig. 6); the right side was the control side and the left side was the experimental side. Due to the variability and the complexity of the phenotype in mutant embryos, we decided to conduct our experimental approach in WT embryos in which anatomical landmarks were consistently identified. This design allowed us to recapitulate the effect of Fgf8 or Wnt3 inhibition that is expressed downstream of Fgf8 (Martinez-Ferre and Martinez 2009). We implanted microbeads embedded in SU5402 to block FGF8 or DKK to block WNT signaling. One day after implanting microbeads embedded in $F g f 8$ signal blocker (SU5402; $n=5$ ), the pERK expression was strongly reduced in the thalamic and ZLI radial gland near the bead (Fig. 6a) compared to the control side, where the beads embedded with DMSO were implanted (Fig. 6b). This indicates that a $F g f 8$ signal is required to maintain pERK expression in radial glia.

Next, to explore potential mechanisms for understanding TML cell death after pERK reduction, we analyzed caspase 3 immunohistochemistry after SU5402 microbead implantation. Cell death was more abundant in the experimental Th $(n=5$; Fig. $6 \mathrm{c}, \mathrm{d}$, e), close to the SU5402 beads (arrows in Fig. 6d, e), than on the control side ( $n=5 ;$ Fig. $5 \mathrm{c}, \mathrm{i})$, confirming that FGF8/pERK signal is required for cell survival in the developing Th. Interestingly, $F g f 8$ activity in the dorsal Th induces Wnt 3 


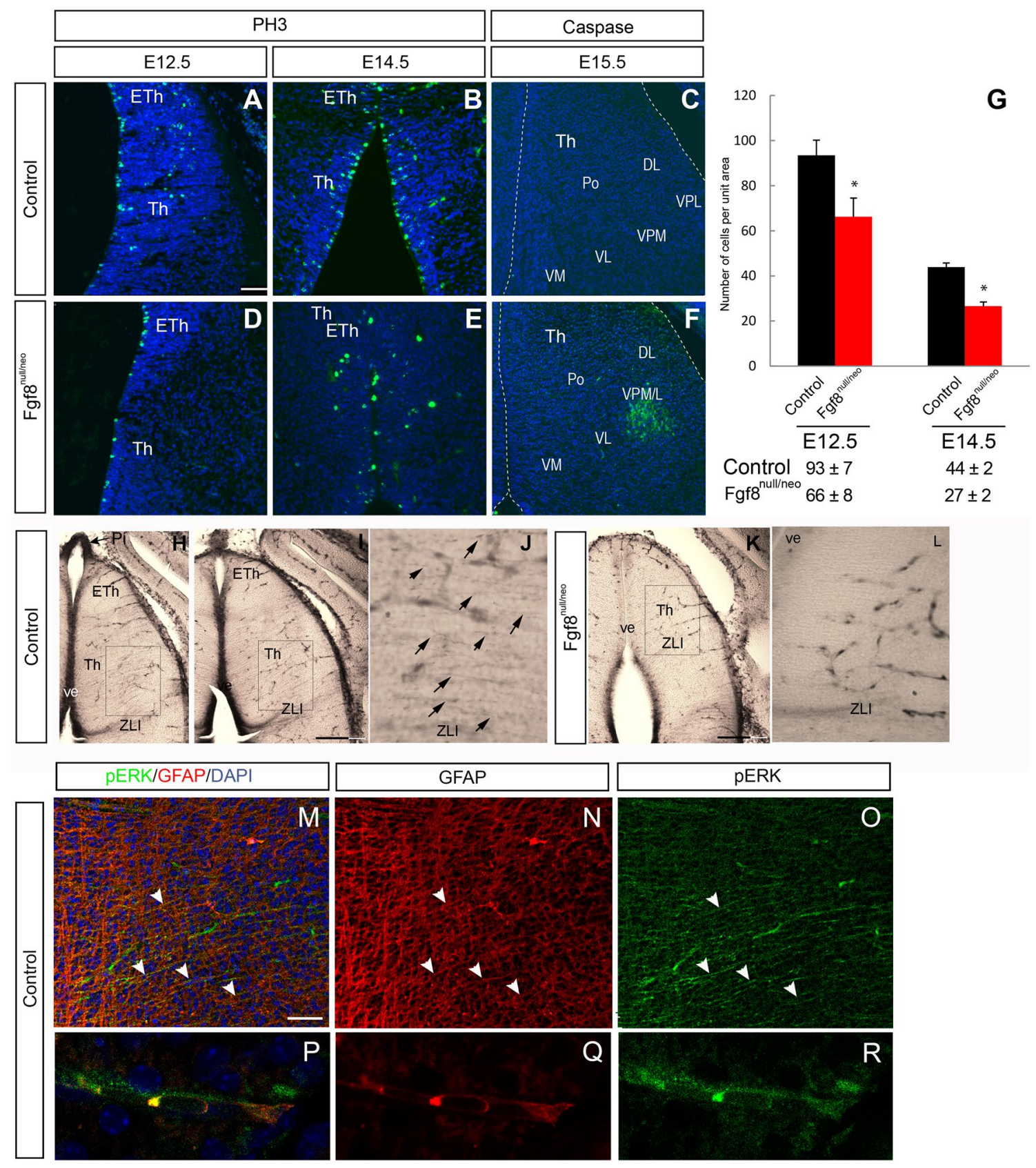

Fig. 5 Proliferation and apoptosis were altered in the diencephalon of $\mathrm{Fgfr}^{\text {null/neo }}$ mutant embryos $(\mathbf{a}, \mathbf{b}, \mathbf{d}, \mathbf{e})$. Immunohistochemistry using an anti-PH3 antibody on transversal sections of the Di revealed severely reduced PH3 immunoreactivity in Fgf8 mutant embryos at E12.5 (a, d) and at E14.5 (b, e). Apoptotic cells were detected by caspase-3 immunofluorescence only in the Fgf8 ${ }^{\text {null/neo }}$ lateral and ventral region of the thalamic mantle layer at E15.5 (f), but not in wt (c). Histograms presenting the average number $( \pm$ SEM) of proliferating cells per unit area, * indicates values that were statistically different $(p<0.05)(\mathrm{g})$. pERK expression in E14.5 control Th, where ventricu-

expression, which was not seen in Fgf8 ${ }^{\text {null/neo }}$ mutant mice (Martinez-Ferre and Martinez 2009); for this reason, we explored the effects of Wnt signaling inhibition by DKK (Wnt antagonist) microbead $(n=6)$ implants. Increased lar epithelium (H and I) and fibers (j) appear immunopositive, as well as blood vessel cells. In Fgf8 $8^{\text {null/neo }}$ mice, the expression of pERK in thalamic fibers is not detected, while vascular expression is remaining $(\mathbf{k}, \mathbf{l})$. Strong pERK expression in Pi was used as a positive control for pERK immunolabelling (arrow in $\mathbf{h}$ ). Double immunohistochemistry (m) against GFAP (red; n, q) and pERK (green; o, r). High-powered image shows double labelling of GFAP and pERK in thalamic radial glia fibers (p). Scale bar: $200 \mu \mathrm{m}$ in $\mathbf{h}, \mathbf{i}$ and $\mathbf{k} ; 50 \mu \mathrm{m}$ in $\mathbf{a}-\mathbf{f}, \mathbf{j}, \mathbf{l}, \mathbf{m}-\mathbf{o}$ and $15 \mu \mathrm{m}$ in $\mathrm{P}-\mathrm{R}$

cell death was induced on the experimental side around the DKK bead (Fig. 6f-h, arrows in G,H), something that was not detected with control implants of PBS-soaked beads (Fig. 6j). 

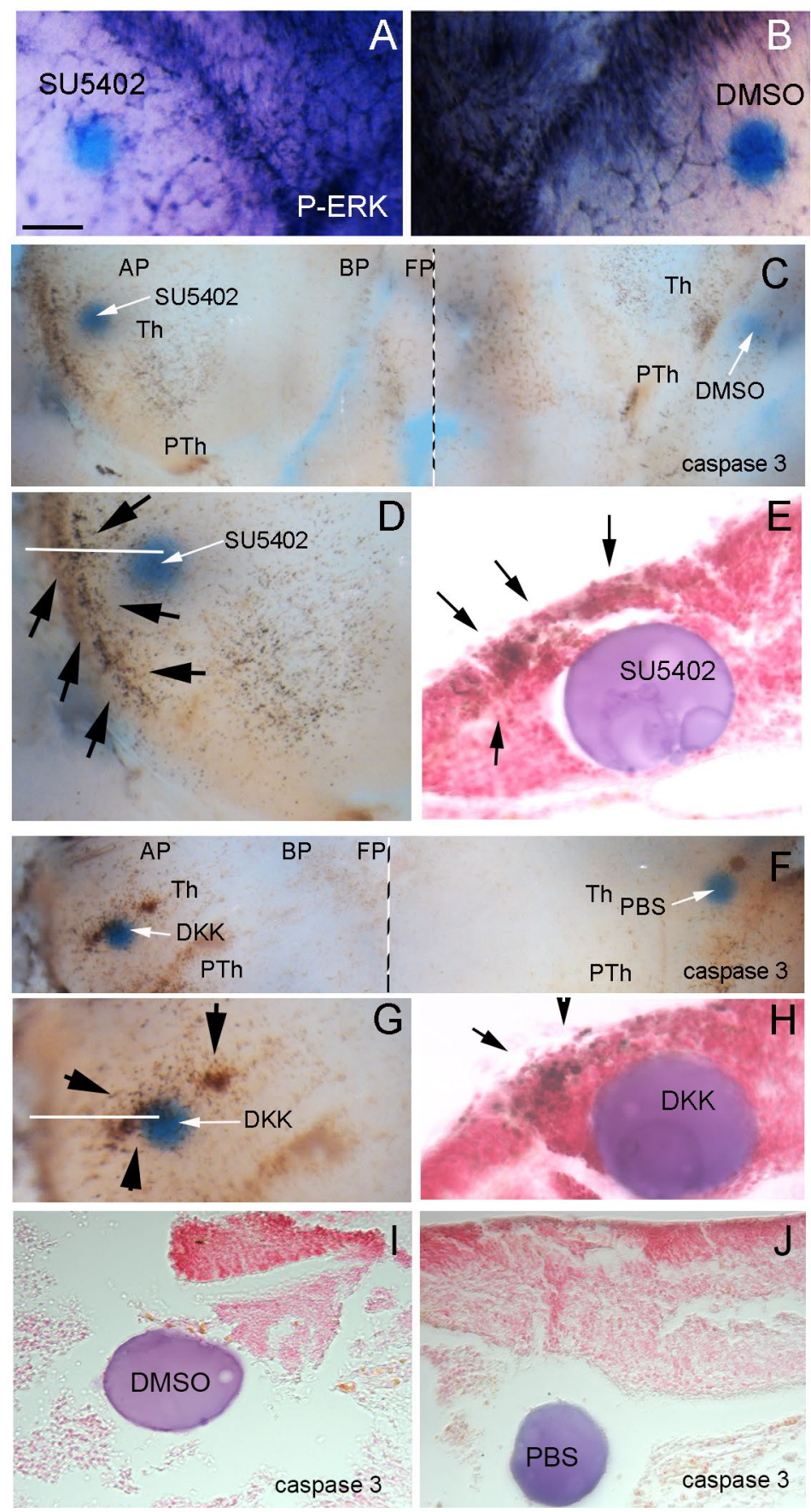

Fig. 6 Fgf8 and Wnt signal loss of function in neuroepithelial mouse explants. a, b The anterior Th and ZLI radial glia cells and fibers strongly express pERK on the control side of the neuroepithelial explants (right side where DMSO control microbead was implanted); after blocking Fgf receptors with a SU5402 bead implant (left side), pERK expression in the thalamic and ZLI radial glia decreases, while radial glia fibers are not detectable in the thalamic mantle layer and the vascular expression remains. c, e After Fgf signal blocking by SU5402 embedded microbeads in the Th, strong increases in caspase-3-expressing cells are detectable around the experimental bead (left side in $\mathbf{c}, \mathbf{d}$ ) in comparison with the control side (right side in c). After sectioning and neutral red staining of the bead and nearby thalamic wall, caspase-3-expressing cells can be seen in both ventricular epithelium and mantle layer cells (e; black arrows in $\mathbf{d}, \mathbf{e}$ ). f, $\mathbf{h}$ After Wnt signal blocking by DKK embedded microbeads in the Th, a strong increase in caspase-3-expressing cells is detectable around the experimental bead (left side in $\mathbf{f}, \mathbf{g}$ ) in comparison with the control side (right side in f). After sectioning and neutral red staining of the bead and nearby thalamic wall, caspase-3-expressing cells can be seen in both ventricular epithelium and mantle layer cells (arrows) Control beads (i, $\mathbf{j}$ ) did not induce caspase 3 expression. $\mathbf{i}$ Corresponds to the control bead for SU5402 experiments (embedded in DMSO) and $\mathbf{j}$ to the DKK experiments (embedded in PBS). Scale bar $200 \mu \mathrm{m}$ in $\mathbf{c}, \mathbf{f}, 170 \mu \mathrm{m}$ in $\mathbf{a}, \mathbf{b}, \mathbf{d}, \mathbf{e} ; 100 \mu \mathrm{m}$ in $\mathbf{i}, \mathbf{j} ; 50 \mu \mathrm{m}$ in $\mathbf{e}, \mathbf{h}$ 


\section{Altered thalamocortical axons in $\mathrm{Fgf8}{ }^{\text {null/neo }}$ mice}

The TC is also a marker for exploring thalamic regionalization, since mutations in thalamic genes ( $G b x 2$ and $S h h)$ significantly alter this tract (Miyashita-Lin et al. 1999; Szabo et al. 2009). Although (Garel et al. 2003) reported that TC was normal in mildly hypomorphic $\mathrm{Fgf} 8^{\text {neo/neo }}$ mice, it is unknown what effect a stronger reduction in the $F g f 8$ signal would have in the TC of Fgf $8^{\text {null/neo }}$ mice. In fact, FGF signals promote the presence of specific guidance cues critical for normal optic tract development (Atkinson-Leadbeater et al. 2010). To explore the potential role of $F g f 8$ reduction in TC development, DiI crystals were implanted into the Th of E16.5 control and mutant mice (Fig. 7). The control TC followed rostrally from the Th to the lateral PTh, peduncular hypothalamus (PHy) and turned dorsally and laterally to enter the subpallium and $\mathrm{Cx}$ along the internal capsule $(n=8$, Fig. 7a, c, e). All the controls $(n=8)$ examined showed similar projection patterns. In contrast, DiI injections in the Fgf8 ${ }^{\text {null/neo }}$ embryos resulted in the derailment of thalamic axons in mutant mice (14/20). These axons followed rostrally towards the anterior forebrain through the PHy, but instead of making a dorsal turn, they continued on an ectopic rostral projection (ep) towards the anterior hypothalamus, into the preoptic area (POA; $n=14$,Fig. 7b, d, f). In $30 \%$ of cases $(n=6)$, some TC axons did turn dorsally and enter the pallium.

\section{Altered Ntn 1 and DCC expression in the thalamocortical pathway of Fgf8 ${ }^{\text {null/neo }}$ mutant mice}

The aberrant projection route of TC detected in the Fgf $8^{\text {null/ }}$ ${ }^{n e o}$ mutant could be due either to a misspecification of projecting thalamic neurons or alterations in the axonal navigation mechanisms. Since thalamic neurons normally send axons through the anterior thalamic peduncle (Fig. 7), the aberrant TC may not be due to a primary neuronal phenotype. Several studies have demonstrated that Netrin 1 (Ntn1) /DCC and Slit 1, 2/Robo1, 2 are important signaling molecules involved in the guidance of thalamocortical axons during embryonic development [reviewed in (LeyvaDíaz and López-Bendito 2013; Leyva-Díaz et al. 2014)]. The gradient expression of Ntn1 in VTel attracts the axons expressing DCC receptors (Powell et al. 2008). For this reason, we have analyzed the expression pattern of long-range guidance signals, the Ntnl gene and its receptor (DCC). At E14.5 in the Di and anterior prosencephalon, Ntnl expression was detected in the periventricular TML, with a gradient decreasing towards the lateral surface, both in control (Fig. 8a, $n=4$ ) and mutant animals (Fig. 8f, $n=4$ ). This may be the signal that induces axonal growth of the thalamic peduncle. However, the expression of Ntnl in the POA and alar hypothalamic ventricular epithelium was downregulated in Fgf8 ${ }^{\text {null/neo }}$ mutants (arrow in Fig. 8a, f). This reduction in
Fig. 7 Abnormal pathfinding of TCAs in Fgf8 ${ }^{\text {null/neo }}$ embryos. a, $\mathbf{b}$ Medial views of the brain hemispheres with DiI crystals in the Th of control (a) and Fgf8 $8^{\text {null/neo }}$ (b) mice brains. c, d Sagittal sections at E16.5 of the corresponding brains after DiI diffusion. e, f Experimental paradigm used to test TCAs in control and $\mathrm{Fgf}^{\text {null/neo }}$ E16.5 embryos; the axonal tract is represented in red. Scale bar: $200 \mu \mathrm{m}$ in $\mathbf{a}, \mathbf{b} ; 150 \mu \mathrm{m}$ in $\mathbf{c}$ and $\mathbf{d}$

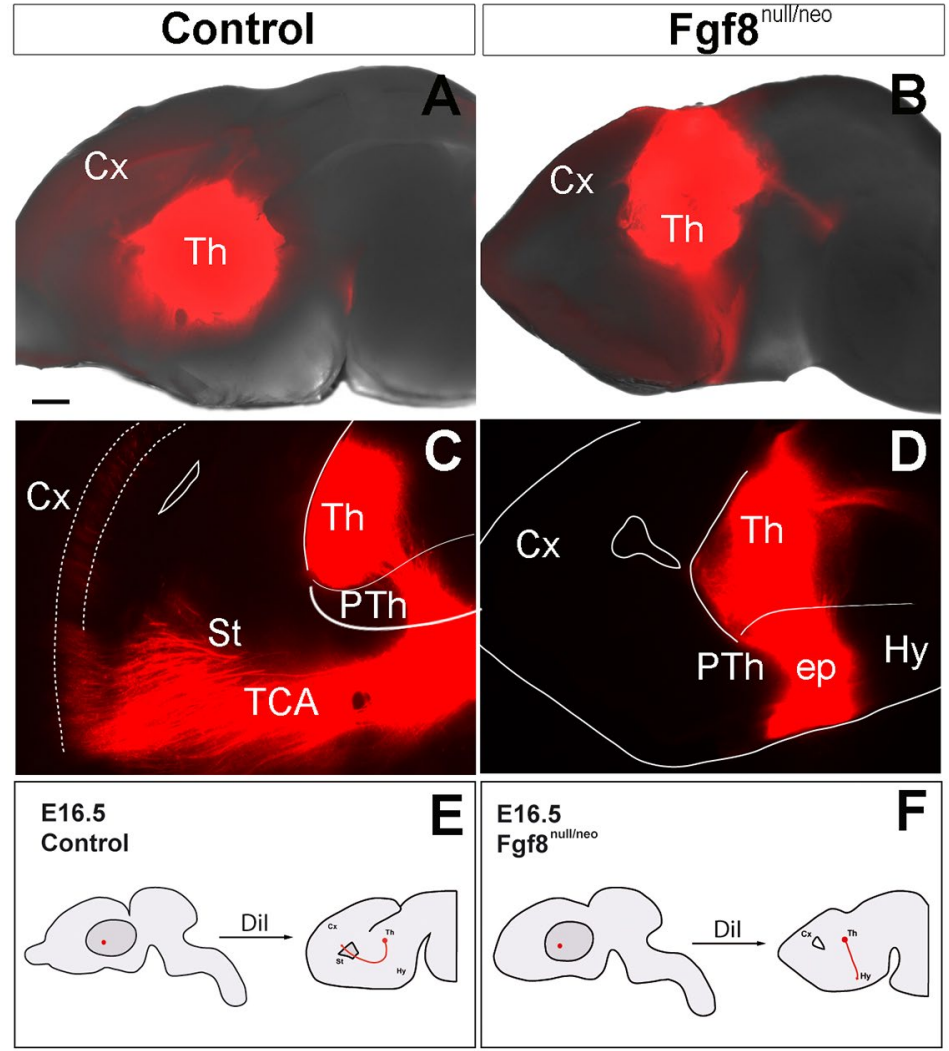


Fig. 8 Altered guidance molecules in Fgf8 $8^{\text {null/neo }}$ mice. Ntn1 $(\mathbf{a}, \mathbf{d}, \mathbf{f}, \mathbf{i}), \operatorname{DCC}(\mathbf{b}, \mathbf{e}, \mathbf{g}, \mathbf{j})$ and pERK $(\mathbf{c}, \mathbf{h})$ immunostaining in transversal sections of control and $\mathrm{Fgf8}{ }^{\text {null/neo }}$ mice at E14.5 and E18.5. The arrows indicate different expression levels of $N t n 1$ in the POA and Hy (a, d). At E18.5, DCC + TCAs entered the $\mathrm{Cx}$ (arrow in e); in Fgf8 mutant DCC + TCAs followed an aberrant path towards the $\mathrm{Hy}$ (arrow in $\mathbf{j}$ ). pERk expression in the radial glia and fibers is strong in Ntnl positive epithelia (GE and POA), as well as in the stria terminalis (ST) and peduncular area, where thalamo-cortical fibers enter the subpallium (arrow). In the mutant, only POA and GE show pERK expression. Ntn11 expression in transverse $(\mathbf{k}, \mathbf{l}, \mathbf{n}, \mathbf{o})$ and sagittal sections $(\mathbf{m}, \mathbf{p})$ of control and $\mathrm{Fgf} 8^{\text {null/neo }}$ mice at E17.5 and E16.5. Arrows indicate the likely direction of the TCAs, following the attracting effect of Ntn1. Dashed lines delimit the regions with strong Ntnl labelling. Ntn1 expression (q, $\mathbf{u})$, Slit 1 expression $(\mathbf{r}, \mathbf{v})$ and colorcoded overlays of hybridizations for Ntn1 (red) and Slit1 (green) $(\mathbf{s}, \mathbf{x})$ in transversal sections of E18.5 control and hypomorph brains. Slit2 expression (t, y) in E18.5 transversal sections of control and mutant mice. Higher magnification view of boxed area in the control and Fgf8 ${ }^{\text {null/neo }}$ embryos $\left(\mathbf{t}^{\prime}, \mathbf{y}^{\prime}\right)$.

Scale bar: $200 \mu \mathrm{m}$
Botella-Lopez_Fig.8
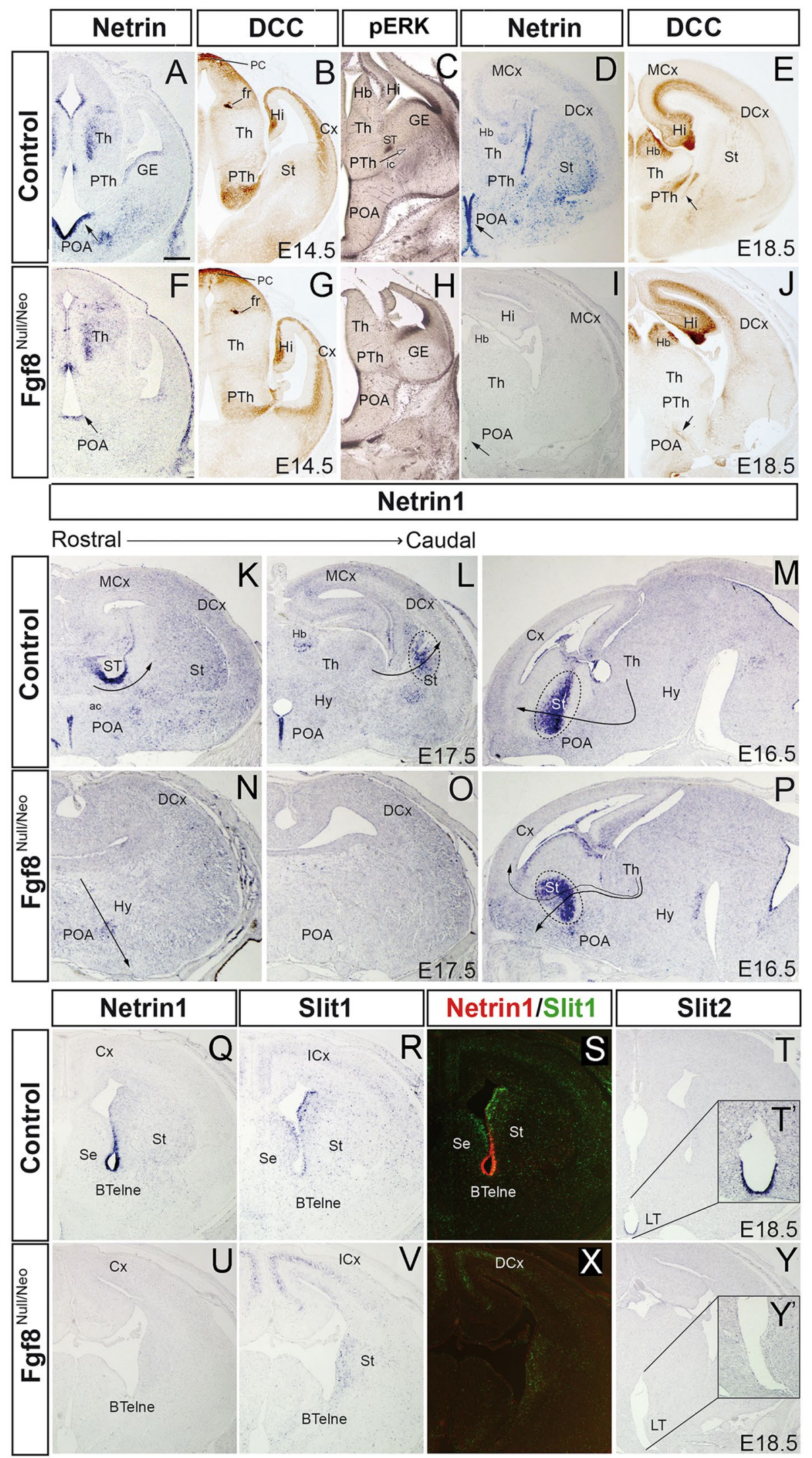
the POA was more pronounced at E18.5 (arrow in Fig. 8d, i; $n=3$ control and 3 mutants). DCC was detected in the PTh (Fig. 8b, $n=3$ ), with less intensity in the mutant mouse (Fig. 8g, n=4). At E18.5, DCC-positive axons were identified in the internal capsule (arrow in Fig. 8e, $n=3$ ); however, in the Fgf $8^{\text {null/neo }}$ mouse, DCC-positive axons followed rostrally along an aberrant pathway into the lateral POA (arrow in Fig. 8j, n=4). In the control telencephalon, Ntnl was also detected in the ventricular epithelium and mantle layer of the bed nucleus of stria terminalis (ST) and the pallidum (Fig. 7i), as well as in the caudal part of the St (Fig. 8i, j). In the mutant brain at E14.5, E16.5, and E18.5, Ntn1 expression was not detected in any of these regions, except in disperse POA cells (Fig. 81). Next, we analyzed its expression in three mutant mice with a mild phenotype, where part of the TC turned to the $\mathrm{Cx}(30 \% ; 6 / 20)$ and part followed the aberrant pathway to the anterior prosencephalic surface. In these mutants, at E16.5, NtnI expression was strongly detected in the peduncular domain of St, in both control (Fig. 8m) and mutant (Fig. 8p) mice. However, the decreasing pallidum-to-striatum gradient observed in WT (Fig. 8m) was misdirected in the mutants, decreasing from the ventricular to a superficial region (Fig. 8p). Then, since the TC axons followed the decreasing Ntnl gradient in the telencephalic peduncle, they were directed towards the pallium in WT and the anterior prosencephalon-POA in the mutant brain. This means that a reduced $F g f 8$ signal is involved in the absence or reduction of $\mathrm{Ntn} 1$ expression in the telencephalic peduncular region and, therefore, in the alteration in the local TC guides. This control of local signal expression by $F g f 8$ signaling may be also driven by pERK expression in radial glia, since strong pERK expression was detected in these regions (Fig. 8c), whereas it was not detected in Fgf ${ }^{\text {null/neo }}$ mice (Fig. 8h).

\section{The co-expression of Netrin 1/Slit 1 was impaired in Fgf8 ${ }^{\text {null/neo }}$ mice}

The expression of the Slits/Slits receptor family (Slit1, Slit2, Robol and Robo2) was also analyzed. These signaling molecules repel the axons expressing Robol/Robo2 when they interact with Slit1/Slit2, deviating them from the hypothalamus and midline (Braisted et al. 2009; Leyva-Díaz and López-Bendito 2013). At E18.5, the control mice expressed Ntn1 in the neuroepithelial zone of the anterior basal telencephalon (BTel) (Fig. 8q, s); however, no signal was detected in Fgf8 ${ }^{\text {null/neo }}$ mutants (Fig. 8u, x). While Slit1 was detected in the SVZ of the St and Septum (Se; Fig. 8r, s) in controls, this gene was only detected in the St of the mutants (Fig. 8v, x). A combined analysis of Ntn 1 and Slit1 expression in a color-coded overlay revealed the complementary expression of these genes in the control BTel (Fig. 8S), but not in the mutant mouse (Fig. 8x). Slit2 expression was detected in the lamina terminalis (LT; Fig. 8t, $\mathrm{t}^{\prime}$ ) in control mice, while it was absent in mutants (Fig. 8y, $\mathrm{y}^{\prime}$ ). No differences in the expression patterns of Robol and Robo 2 were detected between the control and Fgf8 ${ }^{\text {null/neo }}$ embryos (data not shown).

\section{Discussion}

\section{Role of Fgf8 in thalamic regionalization}

Thalamic regionalization is controlled through the molecular specification of progenitors in the $\mathrm{p} 2$ alar plate. The expression of specific cell fate genes is regulated through the distribution of diffusible morphogenetic signals at the ventricular epithelium: FGF8, SHH, WNT and BMP, encoding positional information (Martínez and Puelles 2000; Echevarría et al. 2003; Scholpp et al. 2006; Szabo et al. 2009; Vue et al. 2009; Scholpp and Lumsden 2010; Nakagawa and Shimogori 2012; Bluske et al. 2012; Puelles and Martinez 2013; Martinez-Ferre et al. 2013). This positional information might be translated to the TML, where neurons populate specific nuclear masses. The TML protomap determines the molecular signature that governs hodological differentiation and the function of thalamic neurons. Neurons in the VM/L, receiving primary sensory lemniscal pathways, express the $B t b d 3$ gene, differentiate into c-type neurons and project to layer III and IV of the primary sensorial Cx (Clascá et al. 2012). These regions showed a strong pERK signal requirement for their survival and nuclear segregation (Fig. 9). In the Eurexpress database, the expression of Wnt 3 and pERK is stronger in the ventral and lateral TML than in the dorsal TML at E14.5 (Supplementary Fig. 1, insert), suggesting that pERK may locally increase the Wnt signal. Conversely, ventro-medial and anterior thalamic nuclei are less sensitive to $\mathrm{pERK} / \mathrm{WNT} 3$ signals and require other factors as $\mathrm{SHH}$ and GBX2 (Szabo et al. 2009; Vue et al. 2009; Nakagawa and Shimogori 2012). Neurons in these nuclei receive cerebellar and striatal afferents, and project, as m-type (multiareal) thalamic cells, to layers 5 and 1 of the frontal motor Cx (Clascá et al. 2012). Neurons in the dorsal and posterior nuclei express Igsf 21 differentiate into m-type and il-type neurons and project to superficial and deep cortical layers of medial and caudal association areas (Clascá et al. 2012). In this study, we have demonstrated that neurons in the dorsal and posterior nuclei survive the reduced $F g f 8$ signal and extend rostrally due to re-specification of anterior domains (Fig. 9). As a consequence of inadequate neuronal segregation into nuclear masses, the molecular intrathalamic boundary that differentiates dorsal from ventral nuclei, the thalamic internal medullary lamina did not develop properly.

The selected genes: Igsf21, Pde10 and Btbd3, served as markers to reveal how the neuroepithelial positional map 


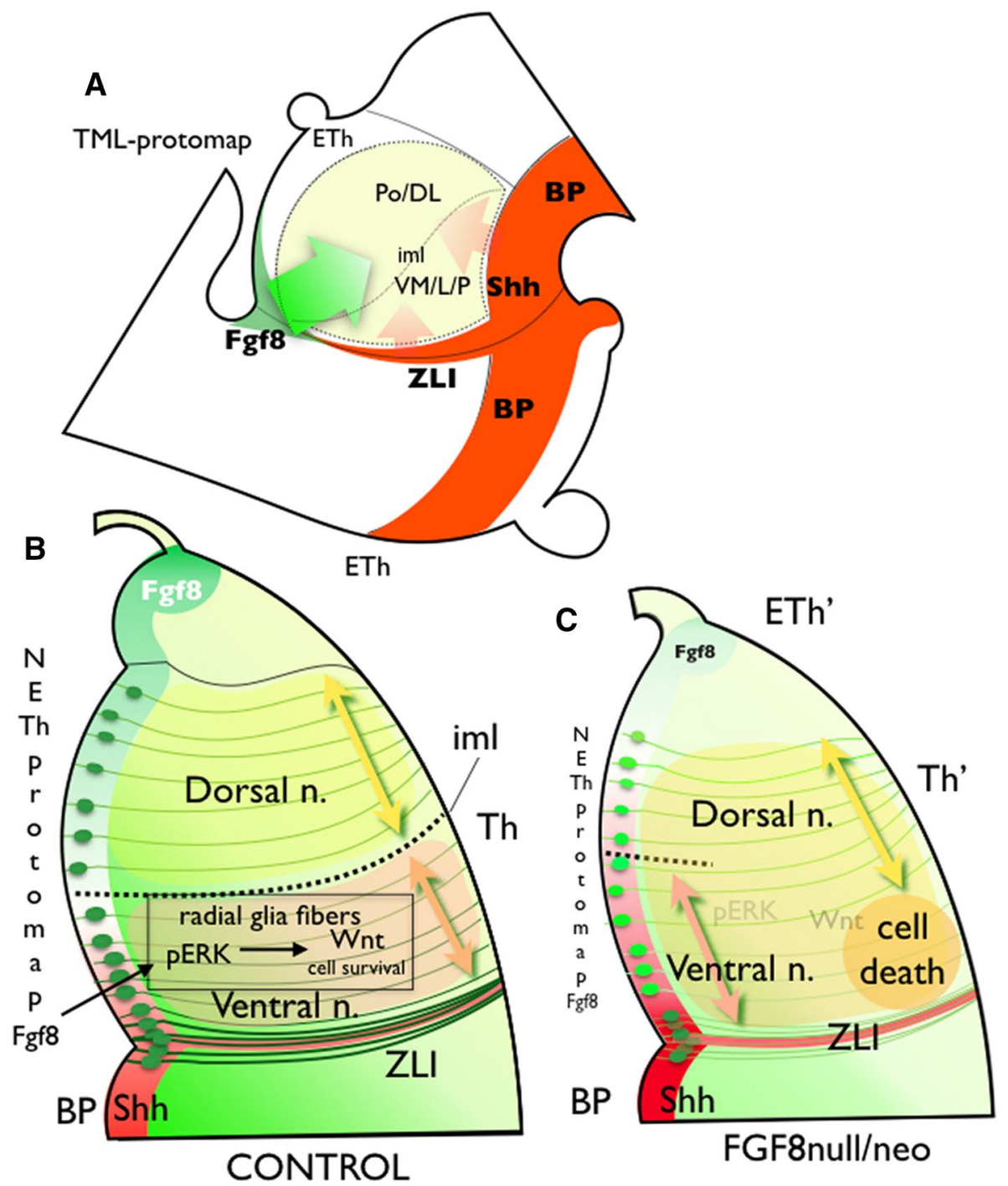

Fig. 9 Schematic representation of the TML protomap in the Fgf8 hypomorph phenotype. a Schematic representation of the TML protomap in a lateral view of E14.5 Di. The internal medullary lamina (iml) separates the dorsal nuclear complex (PoDL) from the ventral nuclear complex (VM/LP). Colored arrows represent the $F g f 8$ gradient signal (green arrow), with the $S h h$ gradient signal (red) acting over TML. b Fgf8 antero/dorso-postero/ventral gradient, together with a $S h h$ complementary gradient, establishes the neuroepithelial and mantle layer molecular maps. Fgf 8 signal acts through a ventricular and neuroepithelial diffusion that activates pERK expression

was propagated to postmitotic neurons of the mantle layer, as postulated by CD15 expression in the human Th (Forutan et al. 2001) and Eomes expression in the Cx (Elsen et al. 2013). In the $\mathrm{Th}$, as previously described in cortical layering (Rakic 2009), the radial glia fibers may represent a scaffold on which to organize the structural complexity of TML development. Through a cell-autonomous signal, radial fibers enable the translation of $2 \mathrm{D}$ positional information from the ventricular epithelium to a $3 \mathrm{D}$ structure in the thalamic in radial glia cells and fibers, allowing the dorsal and ventral nuclei specification and separation by the iml. pERK upregulates Wnt 3 expression, which represents the cell survival signal. c The reduction of $F g f 8$ signaling modifies morphogenetic information and produces a strong reduction of pERK expression in the radial glia with the subsequent absence of Wnt3 activation. This represents cell death in the lateral and ventral $\mathrm{Th}$, as well as abnormalities in thalamic regionalization (Eth' and $\mathrm{Th}^{\prime}$ ), increasing the area occupied by ventral nuclei in the periventricular stratum; and the ventral induction of dorsal markers in intermediate and superficial strata

nuclear complex. The expression of pERK along the radial fibers may be a representation of the $F g f 8$ signaling code, which from the dorsal-anterior thalamic midline and the dorsal ZLI produces different pERK activation levels in ventricular radial glial cells. Although it cannot be assured that FGF8 protein acts in a direct manner on the TML, the reduction of $F g f 8$ expression in diencephalic dorsal midline is bound to a decrease of pERK in TML and to an altered thalamic development. FGF signaling is mediated via 
tyrosine kinase receptors (FGFRs) that act through a number of transduction pathways, like the highly conserved RasERK mitogen-activated protein kinase (MAPK) (reviewed by Niehrs and Meinhardt 2002; Echevarria et al. 2005). Moreover, the absence of $\mathrm{Fgfl} 15$ signal did not show this phenotype (Martinez-Ferre et al. 2016) suggesting that Fgf8 is the direct or indirect signal to maintain pERK expression in radial glia fibers.

Since Wnt 3 expression in the lateral TLM was stronger in the ventral than dorsal nuclear territory (insert in Fig. S2), this may be related to the local specification and survival of ventro-lateral thalamic cells. We have shown that Wnt 3 expression is induced by $F g f 8$ activity in thalamic neuroepithelium (Martinez-Ferre and Martinez 2012). Hence, the FGF8/pERK/WNT signal may be necessary for cell survival. This is in agreement with (Guo et al. 2017), who reported that $\mathrm{pERK}$ activates the $\mathrm{Wnt}$ canonical pathway in cancer cells. Moreover, (Libro et al. 2016) showed that Wnt$\beta$ catenin signal perturbations are associated with cell death in the CNS. Therefore, pERK expression in the radial glia fibers is required to maintain the Wnt signal in TML, which is necessary for the survival of VL Th nuclei.

Gezelius et al. (2016) also demonstrated molecular heterogeneity in the thalamic sensory nuclei at two developmental stages: E14.5 and E18.5. In their screening, they did not detect expression of the three genes we have identified, probably because their analysis method did not generate sufficient transcriptomic differences along expression gradients in reduced volumes.

While no reports analyze the expression of Igsf21 in the brain, $P d e 10$ is a cyclic nucleotide phosphodiesterase (PDE) that determines cyclic nucleotide signaling. PDE signaling regulates cAMP and cGMP concentrations in thalamic neurons in vitro (Hepp et al. 2007), a signaling pathway involved in neuronal plasticity and axonal growth (Mango et al. 2014). More interestingly, Btbd3 expression is involved in the control of dendrite orientation in the mammalian neocortex (Matsui et al. 2013). In fact, Btbd3 expression is enhanced in neuronal regions where functional-related remodeling of connections is required. Thus, the expression of $B t b d 3$ in the Th may be required to develop topological sensorial maps in VL and dorsal geniculate nuclei. We propose that the reduction of $F g f 8$ signal is responsible for the thalamic disorganization and, as a consequence, $\operatorname{Igsf} 21$, Pde10a, Btbd3 showed an altered expression. The demonstrated role of these genes in some developmental processes indicates that more studies are needed to reveal their influence in the regionalization of the thalamus.

$\mathrm{Fgf8}$ expression is involved in the organization of anterior thalamic and prethalamic nuclei (Kataoka and Shimogori 2008), as well as the ETh (Martinez-Ferre and Martinez 2009). Although our previous studies showed that reduced Fgf8 signaling in the Di does not lead to an increase in cell death in early developmental stages [E11.5-13.5; (MartinezFerre and Martinez 2012)], as it occurs in the midbrain/ hindbrain region (Chi et al. 2003), here we detected positive caspase signaling in the ventro-lateral thalamic mantle layer at later stages (E15.5; Fig. 5c, f). Therefore, Fgf8 signaling is required for the survival of thalamic neurons at E15.5 and E17.5, in a dose-dependent manner. Since the thalamic phenotype was detected in regions without cell death marker expression, and cell migration alterations were not observed in our mutants, patterning anomalies in $\mathrm{Fgf} 8^{\text {null/neo }}$ may be a consequence of re-specification (extension of medial and dorsal nuclei) and neuronal death in VL Th.

Our results, therefore, indicate that $F g f 8$ signal levels affect thalamic regionalization, acting on TML neurons. That molecular signaling contribute to the increase of TML complexity by projecting the $2 \mathrm{D}$ ventricular patterning onto a 3D organized structure following differences in signal intensity in radial glia fibers. This 3D pattern is exclusively coded by $F g f 8$ expression, since although $F g f 15$ is expressed in the TML, and regulated by Shh (Gimeno and Martinez 2007), there was no nuclear disorganization in the thalamus of $\mathrm{Fgfl5} / \mathrm{/}$ - mice, and it is not reproduced in $\mathrm{Fgf} 8^{\text {null/neo }}$ mice (Martinez-Ferre et al. 2016).

\section{Thalamocortical Circuit Abnormalities in Fgf8 hypomorphic mice}

In the $\mathrm{Fgf} 8^{\text {null/neo }}$ mutant, the axons leave the Th, cross the PTh and continue to the pPHT, rather than turn to enter the ventral telencephalon and enter the Cx (Braisted et al. 1999; Tuttle et al. 1999). However, only a $30 \%$ of Fgf $8^{\text {null/neo }}$ mice $(6 / 20)$ did present partial distribution of the thalamic axons towards the Cx. Garel et al. (2003) reported a normal TC projection in hypomorphic Fgf $8^{\text {neo/neo }}$ mice. These differences may be explained by the level of Fgf8 reduction, which is $40 \%$ of normal levels in $\mathrm{Fgfr}^{\text {neo/neo }}$ and $20 \%$ in $\mathrm{Fgf8}^{\text {null/neo }}$ (Meyers et al. 1998; Garel et al. 2003).

TC abnormalities, or functional connectivity impairments, have recently been related to various human diseases, such as idiopathic epilepsy (O'Muircheartaigh et al. 2012; Kim et al. 2014), cognitive dysfunction in anorexia (Biezonski et al. 2016), a high risk of psychosis (Anticevic et al. 2015) and autism spectrum disorder (Nair et al. 2013, 2015). Therefore, different degrees of alteration in FGF8 signaling may be involved in the developmental processes underlying the multifactorial mechanisms of these diseases.

\section{Adhesion molecule patterns were altered in the TC pathway of $\mathrm{Fgf8} 8^{\text {null/neo }}$ mice}

In Fgf8 ${ }^{\text {null/neo }}$ mice, thalamic axons seemed incapable of identifying the pathway towards the $\mathrm{Cx}$ and subsequently migrated in the wrong direction. The TC pathway crosses 
distinct territories and requires precisely organized attraction/repulsion signals (Dickson 2002; Molnár et al. 2012; Garel and López-Bendito 2014).

We analyzed the expression of Netrins and Slits and their neuronal receptors (DCC and Robo, respectively) in $\mathrm{Fgf}^{\mathrm{null} / \mathrm{neo}}$ mice. Several studies have shown that Ntn 1 acts as an intermediate target for thalamic axons (Bonnin et al. 2007; Braisted et al. 2000; Culotti and Merz 1998). The long-range gradient of Ntnl in the subpallium is required for the topographic sorting of axons to distinct cortical domains (Powell et al. 2008). In the Fgf8 ${ }^{\text {null/neo }}$ mutant, we demonstrated reduced of $\mathrm{Ntnl}$ expression and the disappearance of its gradient in the St. These changes in Ntnl expression, associated with the lack of radial glia pERK expression, could negatively influence the progression of the thalamo-cortical axons, as previously described by Powell et al. (2008). Congruent with the significance of signal distribution along the radial glia fibers, it has been proven that the Ntnl signal in radial glia fibers at the pial surface guides commissural axons to the ventral midline in the hindbrain (Dominici et al., 2017). Our results strongly suggest that Ntnl expression involved in the dorsal growth of TC to enter into the pallium requires normal pERK expression in the radial glia fibers. Previous work (Stein et al. 2001; Bonnin et al. 2007; Powell et al. 2008) reported that DCC is required to guide rostral thalamic axons to the Ntn1-rich rostral domain of the subpallium. The reduction of DCC expression in Fgf8 hypomorphic mice contributes to the aberrant migration route of the thalamo-cortical axons in $\mathrm{Fgf}^{\text {null/neo }}$ embryos.

Another molecule analyzed in these mutants was Slit (Bielle et al. 2011). Slit1 is highly expressed in the ganglionic eminence (GE) at the stages in which TC fibers are elongating, probably repelling these fibers from the proliferative region (Bagri et al. 2002). Additionally, it has been shown that Slit2 repels thalamic axons in the hypothalamic area, preventing them from invading the hypothalamus (Braisted et al. 1999, 2009; Bagri et al. 2002; López-Bendito et al. 2007). Therefore, the loss of Slit2 expression in the LT of hypomorphic mice allows thalamic axons to invade the anterior hypothalamic region and cross the midline.

Fgf8 signal is involved in the specification of the neural territories where axonal guidance molecules are expressed. Therefore, since receptors of the analyzed molecules were expressed in the axons, it is suggested that the thalamocortical axons themselves develop correctly and they fail in reaching their pathway because of the misexpression of signaling molecules in the intermediate targets such as Ntn 1 or Slits.

In this study, we did not investigate cortico-thalamic axons, which may also be altered in Fgf8 hypomorphic mice; for this reason, we do not know what role these may play in this abnormal projection in the TC anomalies detected (Molnár et al. 1998).

Acknowledgements We would like to thank O. Bahamonde and A. Estirado for their technical assistance. This work was supported by the Spanish Ministry of Science and Innovation grant:FEDER BFU201127326, SAF2014-59347-C2-1-R, and Severo Ochoa Excellence Project SEV-2013-0317; ISCIII: Red TERCEL RD12/0019/0024, and CIBERSAM; GVA: PROMETEO II/2014/014, and the WOP Association.

Funding This work was supported by the Spanish Ministry of Science and Innovation grant:FEDER BFU2011-27326, SAF2014-59347-C21-R, and Severo Ochoa Excellence Project SEV-2013-0317; ISCIII: Red TERCEL RD12/0019/0024, and CIBERSAM; GVA: PROMETEO II/2014/014, and the WOP Association.

\section{Compliance with ethical standards}

Conflict of interest The authors declare they have no conflicts of interest.

Ethical approval All animal experimental assays were performed in compliance with the Spanish and European Union laws on the protection of animals used in experimentation (Council Directive 86/609/ EEC) and approved by the Animal Experimentation Ethics Committee of our university. This article does not involve any studies using human participants.

Open Access This article is distributed under the terms of the Creative Commons Attribution 4.0 International License (http://creativeco mmons.org/licenses/by/4.0/), which permits unrestricted use, distribution, and reproduction in any medium, provided you give appropriate credit to the original author(s) and the source, provide a link to the Creative Commons license, and indicate if changes were made.

\section{References}

Anticevic A, Haut K, Murray JD et al (2015) Association of thalamic dysconnectivity and conversion to psychosis in youth and young adults at elevated clinical risk. JAMA Psychiatry 72:882-891

Atkinson-Leadbeater K, Bertolesi GE, Hehr CL et al (2010) Dynamic expression of axon guidance cues required for optic tract development is controlled by fibroblast growth factor signaling. J Neurosci 30:685-693

Bagri A, Marín O, Plump AS et al (2002) Slit proteins prevent midline crossing and determine the dorsoventral position of major axonal pathways in the mammalian forebrain. Neuron 33:233-248

Bielle F, Marcos-Mondéjar P, Leyva-Díaz E et al (2011) Emergent growth cone responses to combinations of Slit1 and Netrin 1 in thalamocortical axon topography. Curr Biol 21:1748-1755

Biezonski D, Cha J, Steinglass J, Posner J (2016) evidence for thalamocortical circuit abnormalities and associated cognitive dysfunctions in underweight individuals with anorexia nervosa. Neuropsychopharmacology 41:1560-1568

Bluske KK, Vue TY, Kawakami Y et al (2012) $\beta$-Catenin signaling specifies progenitor cell identity in parallel with Shh signaling in the developing mammalian thalamus. Development 139:2692-2702 
Bonnin A, Torii M, Wang L et al (2007) Serotonin modulates the response of embryonic thalamocortical axons to netrin-1. Nat Neurosci 10:588-597

Braisted JE, Tuttle R, O'leary DD (1999) Thalamocortical axons are influenced by chemorepellent and chemoattractant activities localized to decision points along their path. Dev Biol 208:430-440

Braisted JE, Catalano SM, Stimac R, Kennedy TE, Tessier-Lavigne M, Shatz CJ, O'Leary DD (2000) Netrin-1 promotes thalamic axon growth and is required for proper development of the thalamocortical projection. J Neurosci 20:5792-5801

Braisted JE, Ringstedt T, O'Leary DDM (2009) Slits are chemorepellents endogenous to hypothalamus and steer thalamocortical axons into ventral telencephalon. Cereb Cortex 19(Suppl 1):i144-i151

Chi CL, Martinez S, Wurst W, Martin GR (2003) The isthmic organizer signal FGF8 is required for cell survival in the prospective midbrain and cerebellum. Development 130:2633-2644

Clascá F, Rubio-Garrido P, Galazo MJ, Porrero C (2009) Diversity in thalamic relay neurons: evidence for "bottom-up" and "top-down" information flow in thalamocortical pathways. An R Acad Nac Med 126:357-372 (discussion 372-3)

Clascá F, Rubio-Garrido P, Jabaudon D (2012) Unveiling the diversity of thalamocortical neuron subtypes. Eur J Neurosci 35:1524-1532

Culotti JG, Merz DC (1998) DCC and netrins. Curr Opin Cell Biol 10:609-613

Dickson BJ (2002) Molecular mechanisms of axon guidance. Science 298:1959-1964

Echevarria D, Martinez S, Marques S et al (2005) Mkp3 is a negative feedback modulator of Fgf8 signaling in the mammalian isthmic organizer. Dev Biol 277:114-128

Echevarría D, Vieira C, Martínez S (2001) Mammalian neural tube grafting experiments: an in vitro system for mouse experimental embryology. Int J Dev Biol 45:895-902

Echevarría D, Vieira C, Gimeno L, Martínez S (2003) Neuroepithelial secondary organizers and cell fate specification in the developing brain. Brain Res Brain Res Rev 43:179-191

Elsen GE, Hodge RD, Bedogni F et al (2013) The protomap is propagated to cortical plate neurons through an Eomes-dependent intermediate map. Proc Natl Acad Sci 110:4081-4086

Forutan F, Mai JK, Ashwell KW et al (2001) Organisation and maturation of the human thalamus as revealed by CD15. J Comp Neurol 437:476-495

Garel S, López-Bendito G (2014) Inputs from the thalamocortical system on axon pathfinding mechanisms. Curr Opin Neurobiol 27:143-150

Garel S, Huffman KJ, Rubenstein JLR (2003) Molecular regionalization of the neocortex is disrupted in Fgf8 hypomorphic mutants. Development 130:1903-1914

Gezelius H, Moreno-Juan V, Mezzera C et al (2016) Genetic labeling of nuclei-specific thalamocortical neurons reveals putative sensorymodality specific genes. Cereb Cortex. https://doi.org/10.1093/ cercor/bhw290

Ghosh A, Antonini A, McConnell SK, Shatz CJ (1990) Requirement for subplate neurons in the formation of thalamocortical connections. Nature 347:179-181

Gimeno L, Martinez S (2007) Expression of chick Fgf19 and mouse Fgf15 orthologs is regulated in the developing brain by Fgf8 and Shh. Dev Dyn 236:2285-2297

Guo X, Zhang L, Fan Y et al (2017) Oxysterol-binding protein-related protein 8 inhibits gastric cancer growth through induction of er stress, inhibition of WNT signaling, and activation of apoptosis. Oncol Res 25:799-808

Hepp R, Tricoire L, Hu E et al (2007) Phosphodiesterase type 2 and the homeostasis of cyclic GMP in living thalamic neurons. J Neurochem 102:1875-1886
Jones EG (2001) The thalamic matrix and thalamocortical synchrony. Trends Neurosci 24:595-601

Jones EG (2007) The thalamus 2 volume set. Cambridge University Press, Cambridge

Kataoka A, Shimogori T (2008) Fgf8 controls regional identity in the developing thalamus. Development 135:2873-2881

Kim JB, Suh S-I, Seo W-K et al (2014) Altered thalamocortical functional connectivity in idiopathic generalized epilepsy. Epilepsia 55:592-600

Lee SM, Danielian PS, Fritzsch B, McMahon AP (1997) Evidence that FGF8 signalling from the midbrain-hindbrain junction regulates growth and polarity in the developing midbrain. Development 124:959-969

Leyva-Díaz E, López-Bendito G (2013) In and out from the cortex: development of major forebrain connections. Neuroscience 254:26-44

Leyva-Díaz E, del Toro D, Menal MJ et al (2014) FLRT3 is a Robo1interacting protein that determines Netrin-1 attraction in developing axons. Curr Biol 24:494-508

Libro R, Bramanti P, Mazzon E (2016) The role of the Wnt canonical signaling in neurodegenerative diseases. Life Sci 158:78-88

López-Bendito G, Flames N, Ma L et al (2007) Robo1 and Robo2 cooperate to control the guidance of major axonal tracts in the mammalian forebrain. J Neurosci 27:3395-3407

Mango D, Bonito-Oliva A, Ledonne A et al (2014) Phosphodiesterase 10A controls D1-mediated facilitation of GABA release from striato-nigral projections under normal and dopamine-depleted conditions. Neuropharmacology 76 Pt A:127-136

Martínez S, Puelles L (2000) Neurogenetic compartments of the mouse diencephalon and some characteristic gene expression patterns. Results Probl Cell Differ 30:91-106

Martinez-Ferre A, Martinez S (2009) The development of the thalamic motor learning area is regulated by Fgf8 expression. J Neurosci 29:13389-13400

Martinez-Ferre A, Martinez S (2012) Molecular regionalization of the diencephalon. Front Neurosci 6:73

Martinez-Ferre A, Navarro-Garberi M, Bueno C, Martinez S (2013) Wnt signal specifies the intrathalamic limit and its organizer properties by regulating Shh induction in the alar plate. J Neurosci 33:3967-3980

Martinez-Ferre A, Lloret-Quesada C, Prakash N et al (2016) Fgf15 regulates thalamic development by controlling the expression of proneural genes. Brain Struct Funct 221:3095-3109

Matsui A, Tran M, Yoshida AC et al (2013) BTBD3 controls dendrite orientation toward active axons in mammalian neocortex. Science 342:1114-1118

Meyers EN, Lewandoski M, Martin GR (1998) An Fgf8 mutant allelic series generated by Cre- and Flp-mediated recombination. Nat Genet 18:136-141

Miyashita-Lin EM, Hevner R, Wassarman KM et al (1999) Early neocortical regionalization in the absence of thalamic innervation. Science 285:906-909

Molnár Z, Adams R, Blakemore C (1998) Mechanisms underlying the early establishment of thalamocortical connections in the rat. $\mathrm{J}$ Neurosci 18:5723-5745

Molnár Z, Garel S, López-Bendito G et al (2012) Mechanisms controlling the guidance of thalamocortical axons through the embryonic forebrain. Eur J Neurosci 35:1573-1585

Nair A, Treiber JM, Shukla DK et al (2013) Impaired thalamocortical connectivity in autism spectrum disorder: a study of functional and anatomical connectivity. Brain 136:1942-1955

Nair A, Carper RA, Abbott AE et al (2015) Regional specificity of aberrant thalamocortical connectivity in autism. Hum Brain Mapp $36: 4497-4511$ 
Nakagawa Y, O’Leary DDM (2003) Dynamic patterned expression of orphan nuclear receptor genes RORalpha and RORbeta in developing mouse forebrain. Dev Neurosci 25:234-244

Nakagawa Y, Shimogori T (2012) Diversity of thalamic progenitor cells and postmitotic neurons. Eur J Neurosci 35:1554-1562

Navarro-Garberi M, Bueno C, Martinez S (2016) Wnt1 signal determines the patterning of the diencephalic dorso-ventral axis. Brain Struct Funct 221:3693-3708

Niehrs C, Meinhardt H (2002) Modular feedback. Nature 417:35-36

O'Leary DDM, Chou S-J, Sahara S (2007) Area patterning of the mammalian cortex. Neuron 56:252-269

O'Muircheartaigh J, Vollmar C, Barker GJ et al (2012) Abnormal thalamocortical structural and functional connectivity in juvenile myoclonic epilepsy. Brain 135:3635-3644

Pombero A, Garcia-Lopez R, Estirado A, Martinez S (2018) Vascular pattern of the dentate gyrus is regulated by neural progenitors. Brain Struct Funct 223:1971-1987

Powell AW, Sassa T, Wu Y et al (2008) Topography of thalamic projections requires attractive and repulsive functions of Netrin-1 in the ventral telencephalon. PLoS Biol 6:e116

Puelles L, Martinez S (2013) Patterning of the diencephalon. In: Patterning and cell type specification in the developing CNS and PNS. pp 151-172

Puelles L, Rubenstein JL (1993) Expression patterns of homeobox and other putative regulatory genes in the embryonic mouse forebrain suggest a neuromeric organization. Trends Neurosci 16:472-479

Puelles L, Amat JA, Martinez-de-la-Torre M (1987) Segment-related, mosaic neurogenetic pattern in the forebrain and mesencephalon of early chick embryos: I. Topography of AChE-positive neuroblasts up to stage HH18. J Comp Neurol 266:247-268

Rakic P (1988) Specification of cerebral cortical areas. Science 241:170-176

Rakic P (2009) Evolution of the neocortex: a perspective from developmental biology. Nat Rev Neurosci 10:724-735

Redies C (1995) Cadherin expression in the developing vertebrate CNS: from neuromeres to brain nuclei and neural circuits. Exp Cell Res 220:243-256

Redies C, Ast M, Nakagawa S et al (2000) Morphologic fate of diencephalic prosomeres and their subdivisions revealed by mapping cadherin expression. J Comp Neurol 421:481-514

Scholpp S, Lumsden A (2010) Building a bridal chamber: development of the thalamus. Trends Neurosci 33:373-380
Scholpp S, Wolf O, Brand M, Lumsden A (2006) Hedgehog signalling from the zona limitans intrathalamica orchestrates patterning of the zebrafish diencephalon. Development 133:855-864

Sherman SM, Guillery RW (2011) Distinct functions for direct and transthalamic corticocortical connections. J Neurophysiol 106:1068-1077

Squarzoni P (2015) Neuronal and microglial regulators of cortical wiring: usual and novel guideposts. Front Neurosci. https://doi. org/10.3389/fnins.2015.00248

Stein E, Zou Y, Poo M, Tessier-Lavigne M (2001) Binding of DCC by netrin- 1 to mediate axon guidance independent of adenosine $\mathrm{A} 2 \mathrm{~B}$ receptor activation. Science 291:1976-1982

Storm EE, Rubenstein JLR, Martin GR (2003) Dosage of Fgf8 determines whether cell survival is positively or negatively regulated in the developing forebrain. Proc Natl Acad Sci 100:1757-1762

Stoykova A, Gruss P (1994) Roles of Pax-genes in developing and adult brain as suggested by expression patterns. J Neurosci 14:1395-1412

Sun X, Mariani FV, Martin GR (2002) Functions of FGF signalling from the apical ectodermal ridge in limb development. Nature 418:501-508

Suzuki-Hirano A, Harada H, Sato T, Nakamura H (2010) Activation of Ras-ERK pathway by Fgf8 and its downregulation by Sprouty 2 for the isthmus organizing activity. Dev Biol 337:284-293

Szabo N-E, Zhao T, Zhou X, Alvarez-Bolado G (2009) The role of sonic hedgehog of neural origin in thalamic differentiation in the mouse. J Neurosci 29:2453-2466

Tuttle R, Nakagawa Y, Johnson JE, O’Leary DD (1999) Defects in thalamocortical axon pathfinding correlate with altered cell domains in Mash-1-deficient mice. Development 126:1903-1916

Vue TY, Bluske K, Alishahi A et al (2009) Sonic hedgehog signaling controls thalamic progenitor identity and nuclei specification in mice. J Neurosci 29:4484-4497

Xu J, Liu Z, Ornitz DM (2000) Temporal and spatial gradients of Fgf8 and Fgf17 regulate proliferation and differentiation of midline cerebellar structures. Development 127:1833-1843

Yamauchi K, Mizushima S, Tamada A et al (2009) FGF8 signaling regulates growth of midbrain dopaminergic axons by inducing semaphorin 3F. J Neurosci 29:4044-4055 